\title{
An autophagy-inducing and TLR-2 activating BCG vaccine induces a robust protection against tuberculosis in mice
}

Arshad Khan ${ }^{1}{ }^{1}$, Pearl Bakhru ${ }^{1}$, Sankaralingam Saikolappan ${ }^{2}$, Kishore Das ${ }^{2}$, Emily Soudani ${ }^{1}$, Christopher R. Singh ${ }^{1}$, Jaymie L. Estrella ${ }^{1}$, Dekai Zhang ${ }^{3}$, Chandrashekhar Pasare $\mathbb{D}^{4}$, Yue $\mathrm{Ma}^{5}$, Jianjun Sun ${ }^{5}$, Jin Wang ${ }^{6}$, Robert L. Hunter ${ }^{1}$, N. Tony Eissa ${ }^{7}$, Subramanian Dhandayuthapani ${ }^{2}$ and Chinnaswamy Jagannath ${ }^{1,6}$

Mycobacterium bovis BCG is widely used as a vaccine against tuberculosis due to M. tuberculosis (Mtb), which kills millions of people each year. BCG variably protects children, but not adults against tuberculosis. BCG evades phagosome maturation, autophagy, and reduces MHC-II expression of antigen-presenting cells (APCs) affecting T-cell activation. To bypass these defects, an autophagyinducing, TLR-2 activating C5 peptide from Mtb-derived CFP-10 protein was overexpressed in BCG in combination with Ag85B. Recombinant $\mathrm{BCG}^{85 \mathrm{C} 5}$ induced a robust $\mathrm{MHC}$-II-dependent antigen presentation to $\mathrm{CD} 4 \mathrm{~T}$ cells in vitro, and elicited stronger $\mathrm{T}_{\mathrm{H}} 1$ cytokines (IL-12, IL-1 $\beta$, and TNFa) from APCs of C57BI/6 mice increasing phosphorylation of p38MAPK and ERK. BCG ${ }^{85 C 5}$ also enhanced MHC-II surface expression of MФs by inhibiting MARCH1 ubiquitin ligase that degrades MHC-II. BCG ${ }^{85 C 5}$ infected APCs from MyD88 or TLR-2 knockout mice showed decreased antigen presentation. Furthermore, BCG ${ }^{85 C 5}$ induced LC3-dependent autophagy in macrophages increasing antigen presentation. Consistent with in vitro effects, $\mathrm{BCG}^{85 \mathrm{C} 5}$ markedly expanded both effector and central memory T cells in C57BI/6 mice protecting them against both primary aerosol infection with Mtb and reinfection, but was less effective among TLR-2 knockout mice. Thus, BCG ${ }^{85 C 5}$ induces stronger and longer lasting immunity, and is better than BCG against tuberculosis of mice.

npj Vaccines (2019)4:34; https://doi.org/10.1038/s41541-019-0122-8

\section{INTRODUCTION}

Mycobacterium tuberculosis (Mtb) causes eight million new cases of tuberculosis and kills about two million people each year. HIV-1induced CD4 depletion and emergence of multidrug-resistant (MDR) Mtb strains have aggravated the issue. Bacille CalmetteGuérin (BCG) is a widely used vaccine against tuberculosis, although meta-analysis of vaccination shows an unacceptably large variation in protective efficacy in children (0-80\%), and again a variable efficacy against adult disease. ${ }^{1}$ BCG protected adults in certain geographic regions like the United Kingdom, while it seems to have failed in many developing countries. Its variable efficacy is multifactorial, including absence of the major immunogenic region of difference- 1 (RD1) encoded antigens ESAT- 6 and CFP-10 in BCG; variable expression of other antigens like MPT64 among sub-strains of BCG; and exposure of humans to environmental mycobacteria, thought to pre-sensitize and shift vaccine responses from $T_{H} 1$ to $T_{H} 2$ responses. ${ }^{2}$ Since $B C G$ vaccine is safe, improving its immunogenicity appears to be a reasonable approach, although we and others have also generated Mtbderived attenuated candidate vaccines. ${ }^{3-5}$ Many studies describe recombinant BCG strains with increased immunogenicity. ${ }^{6}$ Animal models indicate that both CD4 and CD8 T cells are important for immunity against tuberculosis. ${ }^{7}$ In humans, CD4 T cells appear to be critical since HIV-1-induced depletion leads to tuberculosis coinfection and increased death. On the other hand, CD8 T cells seem to contribute to long-term protection against tuberculosis in humans.

In our previous studies, we sought to determine the molecular basis of BCG-induced variable protection. Following vaccination, dendritic cells (DCs) and macrophages (MФs) phagocytose BCG, process antigens within either proteasomes or lysosomes and present them, respectively, to activate CD8 and CD4 T cells. Interestingly, the standard mouse model for tuberculosis vaccination shows that protection correlates better with CD4 T cells than CD8 T cells. ${ }^{7}$ However, even among mice BCG generates only a modest protection against tuberculosis decreasing the lung burden of Mtb by about a $\log _{10}$. We, therefore, hypothesized that despite containing most antigens similar to Mtb, BCG is not efficiently processed and presented within antigen-presenting cells (APCs) like DCs and MФs. This was strengthened by the suggestion that there were defects in antigen transfer between APCs and T cells. ${ }^{8}$ Our previous studies investigated the mechanisms of intracellular antigen processing and $T$ cell activation to determine efficacy of the BCG and Mtb-derived vaccines. Non-pathogenic mycobacteria are taken up into phagosomes, which are sorted to fuse with lysosomes through a series of

\footnotetext{
${ }^{1}$ Department of Pathology and Laboratory Medicine, University of Texas Health Sciences Center, Houston, $\mathrm{TX}$, USA; ${ }^{2}$ Molecular and Translational Medicine, Paul L. Foster School of Medicine Texas Tech University Health Sciences Center, EI Paso, TX, USA; ${ }^{3}$ Institute of Biosciences and Technology, Texas A\&M University Health Science Center, Houston, TX, USA; ${ }^{4}$ Division of Immunobiology, Center for Inflammation and Tolerance, Cincinnati Children's Hospital Medical Center, Cincinnati, OH 45229 , USA; ${ }^{5}$ Department of Biological Sciences

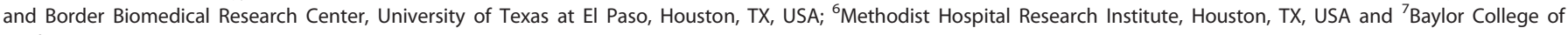
Medicine, Houston, TX, USA

Correspondence: Subramanian Dhandayuthapani (S.Dhandayuthapani@ttuhsc.edu) or Chinnaswamy Jagannath (Chinnaswamy.Jagannath@uth.tmc.edu)

These authors contributed equally: Arshad Khan, Pearl Bakhru, Subramanian Dhandayuthapani, Chinnaswamy Jagannath
}

Received: 28 June 2018 Accepted: 15 May 2019

Published online: 05 August 2019 
maturation events regulated by $r a b$ and SNARE proteins. However, both BCG vaccine and Mtb interfere with phagosome maturation through multiple mechanisms including the secretion of sapM phosphatase, which dephosphorylates phosphatidyl-inositol-3 kinase (PI-3K), a key initial trigger for phagosome maturation. ${ }^{9-12}$ We then demonstrated the molecular basis for decreased antigen presentation by BCG vaccine by demonstrating that Cathepsin-D cleaved secreted Ag85B and that sequestration of BCG in their near neutral $\mathrm{pH}$ phagosomes prevented efficient in situ digestion of Ag85B. ${ }^{13}$ We, therefore, established a direct link between "maturation arrest of BCG vaccine phagosomes and antigen presentation" particularly since Ag85B is an immunodominant component of Mtb that has been used frequently in subunit vaccines.

Interestingly, mammalian autophagy, which is regulated by a series of Atg genes, is another mechanism that delivers vaccines and pathogens to lysosomes, facilitating their degradation and antigen presentation. We reported the novel paradigm that inducing autophagy facilitates MHC-II-dependent mycobacterial antigen presentation to APCs, ${ }^{14}$ which was followed by the demonstration that autophagy-mediated MHC-I antigen presentation. ${ }^{15}$ In our study, rapamycin-induced autophagy improved delivery of BCG vaccine to lysosomes, better antigen presentation to both CD4 and CD8 T cells and markedly improved efficacy against tuberculosis in mice. ${ }^{14}$ Our discovery that the autophagyinducing drug rapamycin increased the efficacy of BCG vaccine has been translated to human studies, as rapamycin enhanced the responses to flu vaccine among human elderly. ${ }^{16}$ Rapamycin is also a lead host-directed therapy agent to improve $M \Phi$ function during tuberculosis, although it also improves T-cell memory. ${ }^{17}$ In parallel with these studies on BCG, we also developed a lysosomefusion competent mutant Mtb $(\triangle f b p A)$, which was more effective than BCG against tuberculosis in mice, and subsequently developed an $\triangle f b p A \Delta s a p M$ candidate vaccine that enhanced the immunogenicity of MФs in vitro and in mice. ${ }^{18,19}$

Although rapamycin enhanced the efficacy of BCG vaccine in mice, and that of flu vaccine in elderly humans, ethical considerations prevent its administration to infants. Thus in this study, we sought to improve the BCG vaccine through genetic engineering. Our earlier studies showed that overexpression of $\mathrm{Ag} 85 \mathrm{~B}$ in $\mathrm{BCG}\left(\mathrm{BCG}^{85 \mathrm{~B}}\right.$; aka. $\left.\mathrm{rBCG} 30\right)$ triggered aggresome formation in APCs that triggered autophagy. ${ }^{20}$ Here, we explored whether we can genetically engineer a recombinant $B C G$ vaccine capable of inducing autophagy.

Both Mtb and BCG secrete many immunogenic proteins, although BCG lacks the RD1 complex encoding ESAT-6 and CFP10 , which may, explain in part, its reduced immunogenicity in mice and humans. ${ }^{21}$ Indeed, ESAT- 6 subunit vaccine provides protection against tuberculosis in mice comparable with BCG vaccine, and a recombinant BCG vaccine expressing ESAT- 6 and Ag85B showed better protection than wt-BCG. ${ }^{22-24}$ Paradoxically, ESAT- 6 inhibits IFN- $\gamma$ responses of mouse and human $T$ cells in vitro, also suppressing TLR-2-dependent phosphorylation of ERK in MФs. ${ }^{25-27}$ Since ESAT-6 is secreted along with CFP-10 antigen by $\mathrm{Mtb}$ and form complexes at neutral $\mathrm{pH}$, we sought to characterize the immunogenicity of this complex. We hypothesized that when ESAT- 6 and CFP-10 complexes are internalized by APCs, their hidden domains may become separated in acidic $\mathrm{pH}$ of the endosomes, exposing their immunogenic and suppressive motifs. We demonstrate in this study that both CFP-10 and ESAT- 6 proteins contain TLR-2 activating peptide motifs, one of which also induced autophagy. An autophagy-inducing, TLR-2 stimulating peptide (TSP) of CFP-10 was then co-expressed along with Ag85B in BCG to yield a novel $B C G^{85 C 5}$ vaccine. $B C G^{85 C 5}$ induced a stronger protection than wt-BCG against tuberculosis in mice, through expansion of $\mathrm{CD}_{2} \mathrm{~L}^{-} \mathrm{CCR} 7^{-} \mathrm{CD} 44^{\text {hi }} \mathrm{CD} 127^{+/-}$effector $\mathrm{T}$ cells $\left(\mathrm{T}_{\mathrm{EM}}\right)$ and $\mathrm{CD} 62 \mathrm{~L}^{+} \mathrm{CCR} 7^{+/}-\mathrm{CD} 44^{\mathrm{hi}} \mathrm{CD} 127^{+}$central memory $T$ cells $\left(T_{C M}\right)$, correlating with $\geq 1.5 \log 10$ reduction in colony counts of Mtb in the lungs and spleens following infection or reinfection. Thus, autophagy induction and TLR-2 stimulation during BCG vaccination markedly improves its efficacy and longevity of protection through a combination of enhanced APC-T cell interaction and in vivo expansion of memory $T$ cells.

\section{RESULTS}

CFP-10 and ESAT- 6 proteins differ in activating APCs in vitro

The protein sequence and overlapping peptides synthesized for CFP-10 and ESAT-6 are shown in Fig. 1a, b. ${ }^{28}$ Peptides were synthesized in two stages; those labeled $\mathrm{C} 1-\mathrm{C} 11$ were initially synthesized, and evaluated for their ability to stimulate APCs as indicated in Fig. 1c-e and Fig. 2a-f. Both CFP-10 and ESAT-6 antigens induce $T$ cells and antibodies during tuberculosis of mice and humans, and are highly immunogenic. Paradoxically, ESAT-6 but not CFP-10 inhibits IFN- $\gamma$ responses of mouse and human T cells in vitro. ${ }^{27}$ In addition, ESAT-6 suppresses MФ signaling through TLR-2-dependent phosphorylation of ERK. ${ }^{25-27} \mathrm{Mtb}$ secretes CFP-10 and ESAT- 6 together, and they are thought to form a tight complex at neutral $\mathrm{pH}^{29,30}$ We therefore examined the hypothesis that CFP-10 and ESAT-6 may exert individual effects, while their complexes have a different effect on APCs. ${ }^{31-33}$ We exploited the ability of APCs to process mycobacterial peptides and activate CD4 T cells via the MHC-II pathway to amplify $T_{H} 1$ immunity. ${ }^{34}$ An in vitro model of antigen presentation has been described where mouse APCs infected with Mtb or BCG vaccine present the peptide-25 epitope of secreted Ag85B to CD4 T cells (BB7 hybridoma). ${ }^{13,35,36}$ APCs were treated with CFP-10 and ESAT-6 proteins followed by BCG infection and overlaid with $T$ cells to detect antigen presentation. Figure 1c illustrates that CFP-10 enhanced the ability of APCs to present antigen to CD4 $T$ cells, whereas ESAT-6 showed an inhibition. A constant stimulatory dose of CFP-10 (around $0.5 \mu \mathrm{M}$ ) was then mixed with increasing amounts of ESAT- 6 at $37^{\circ} \mathrm{C}$ to enable complex formation, and incubated for $15 \mathrm{~min}$ prior to adding to APCs. ESAT-6 suppressed the stimulatory effects of CFP-10 on MDs and DCs (Fig. 1d). A reverse combination was also tested. Since crystallographic studies suggest that CFP-10 and ESAT-6 form tight complexes at neutral $\mathrm{pH}^{29,37,38}$ these data indicate that CFP10 has the ability to stimulate APCs but its activity is likely blocked by complex formation with ESAT- 6 . In additional studies, three truncated peptides of ESAT- 6 were prepared where the N- (E1), C(E2), and both $\mathrm{N}$ - and C-termini (E3) were truncated. These were mixed with intact CFP-10 protein and added to MФs for evaluation of antigen presentation. Figure 1e demonstrates that ESAT-6 lacking either $\mathrm{N}$ - or C-termini (E1; E2) still inhibited CFP-10 enhanced antigen presentation, while E3 failed to inhibit the stimulatory effect of CFP-10. Similar effects were observed for mouse bone marrow-derived DCs (unpublished observations).

Peptide moieties of CFP-10 and ESAT-6 proteins are immuneenhancers for APCs

Although ESAT-6 suppresses mouse and human T-cell secretion of IFN- $\gamma$, it elicits strong T-cell responses in animal models and humans, and is therefore, a candidate vaccine antigen and indeed has been cloned into BCG. ${ }^{39}$ On the other hand, CFP-10 elicits robust $\mathrm{T}$-cell responses in mice, reactive with $\mathrm{T}$ cells from humans with tuberculosis and does not have immune-suppressive activity. ${ }^{40,41}$ To explain the ambiguity in immunogenicity of these proteins, we proposed that their intracellular processing generated immunogenic moieties within APCs.

APCs were therefore, treated with synthetic overlapping peptides of these proteins followed by BCG infection, and in vitro antigen presentation as described previously. Figure $2 \mathrm{a}$, b show two striking observations. The stimulatory activity of CFP10 was localized to $50-70_{\text {aa. }}$. In contrast, the intact ESAT- 6 protein 
a CFP10

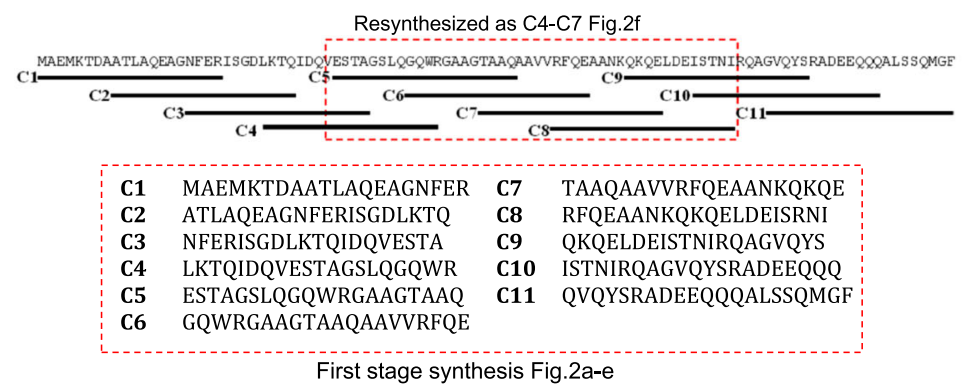

b ESAT-6

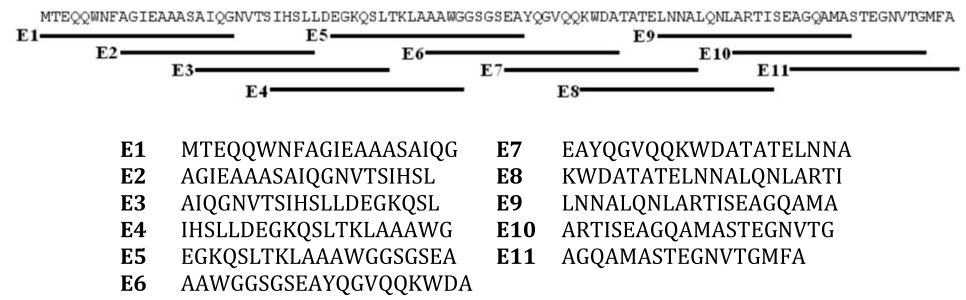

C
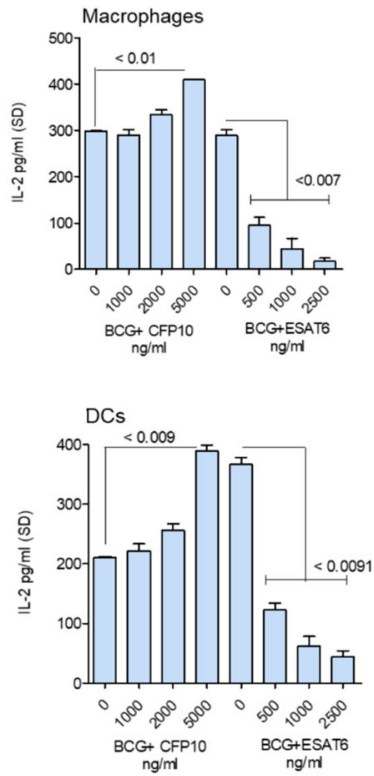

d

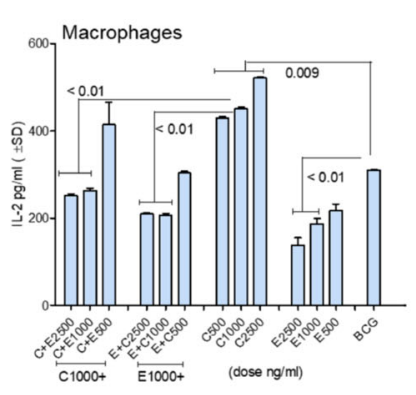

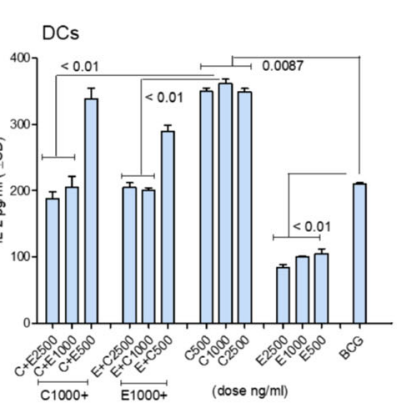

$\mathbf{e}$

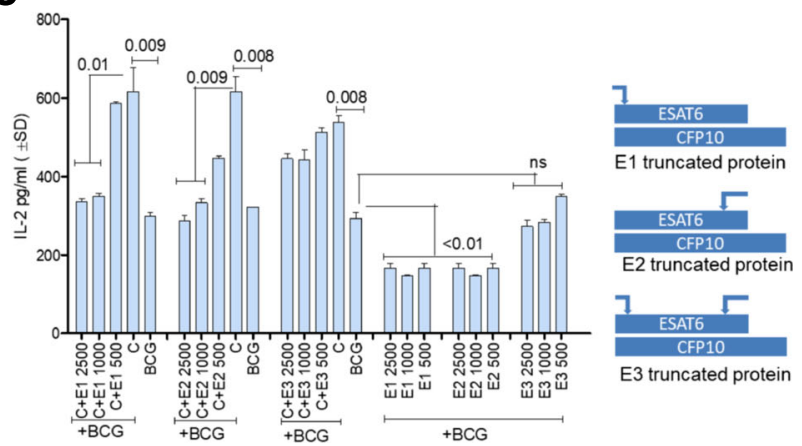

Fig. 1 Mycobacterium tuberculosis (Mtb)-derived CFP-10 and ESAT-6 proteins show a differential activation of antigen-presenting cells in vitro. a, b Amino acid sequences of the whole proteins and overlapping peptides synthesized from CFP-10 and ESAT-6 are shown. CFP-10-derived first-stage synthesis peptides were subjected to an ELISA validation for their ability to stimulate antigen presentation (lower box), and "resynthesized" as peptides C4-C7 (upper box) and ELISA validation of the peptide designated as C5 in Fig. 2f. c C57BI/6 mouse bone marrowderived macrophages (MФs) and dendritic cells (DCs) (APCs) were treated with recombinant CFP-10 and ESAT- 6 whole proteins (BEI Resources Repository, NIH) at doses indicated, followed by infection with Mycobacterium bovis BCG (Pasteur; MOI=1), and overlaid with antigen-85Bspecific CD4 BB7 hybridoma T cells, for antigen presentation. The supernatants were tested for IL-2 levels using sandwich ELISA (one of three similar experiments shown; $p$-values, one-way ANOVA with Dunnett's multiple comparisons post test). d A constant amount of CFP-10 (C; $0.5 \mu \mathrm{M}$; eq.ng/mL indicated) was mixed with ESAT- 6 (E) in varying amounts (0.5-2.0 $\mu \mathrm{M})$ in PBS at $37^{\circ} \mathrm{C}$ for 15 min and added to MФs, followed by infection with BCG and antigen presentation. CFP-10 and ESAT- 6 were added alone as internal controls. Addition of ESAT- 6 reduces the ability of CFP-10 to enhance in vitro antigen presentation (two experiments, ${ }^{*} p$-values, one-way ANOVA with Dunnett's post test). e Three truncated proteins of ESAT-6 protein were prepared and added to CFP-10 protein with BCG vaccine, and antigen presentation determined using MФs. The inhibitory motif of ESAT-6 lies near N-terminus (E1) and extends to middle (E2), but not at C-terminus (E3). Potential binding to CFP-10 is shown, which allows CFP-10 C-terminus to extend. Arrows above the ESAT- 6 indicate the truncated regions

showed inhibitory activity (Fig. 1c). However, distinct peptides of ESAT-6, located both in the $\mathrm{N}$-and the C-terminal region, strongly stimulated APCs to present Ag85B to BB7 T cells (Fig. 2a, b). None of the peptides elicited IL-2 from BB7 $T$ cells overlaid on uninfected APCs (Supplementary Fig. S1). Furthermore, APCs treated with a combination of peptides with BCG, but not peptides alone at doses $<2 \mu \mathrm{M}$, induced elevated levels of IL-12, TNFa and IL-1 $\beta$, cytokines that boost $\mathrm{T}_{\mathrm{H}} 1$ immunity (Fig. 2c-f). In addition, the $T_{H} 1$ cytokine stimulating activity of CFP-10 and ESAT6-derived peptides correlated with their ability to enhance antigen presentation (Fig. 2a, b vs. 2d, e) (Supplementary Fig. S2).

Since ESAT- 6 protein inhibited antigen presentation by APCS (Fig. 1c), the CFP-10-derived immune-stimulatory peptides (red highlighted; Fig. 1a) were selected for further analysis. Overlapping peptides of the region $35-75_{a a}$ of CFP-10 were resynthesized and evaluated. A stretch of synthetic peptide named C5 (MW 2188.41, Genscript, USA; Fig. 2f; red highlighted) was identified as the optimal immune-stimulatory motif of the CFP-10 protein. It was then compared with E3 and E11 peptides and used for all studies described below.

CFP-10 and ESAT-6-derived TLR-stimulating mycobacterial peptides (TSPs) regulate $\mathrm{MHC}-\mathrm{II}-\bar{d}$ ependent antigen presentation and cytokine secretion through MyD88 and TLR-2

The mechanisms of action for TSPs were next investigated. Ag85B presentation assays were performed using MyD88 and TLR-2 knockout (TLR-2-KO) MФs and DCs. The immune-enhancing activity of C5, E3, and E11 peptides was significantly decreased in MФs and DCs of MyD88-KO and TLR-2-KO mice (Fig. 3a-d). Moreover, unlike wild type MФs and DCs infected with TSP-BCG 


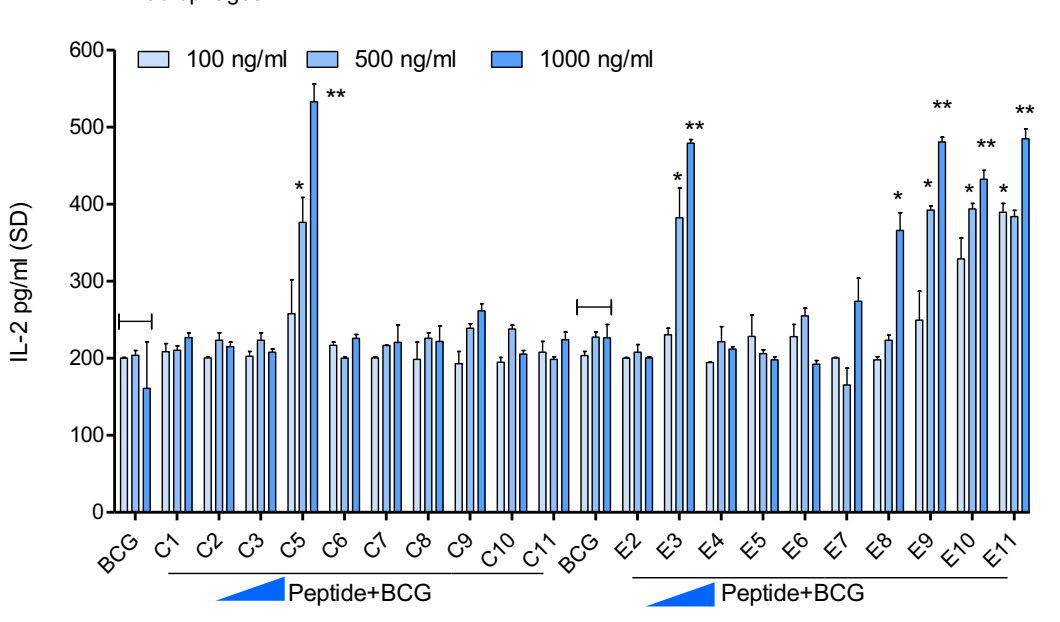

b DCs

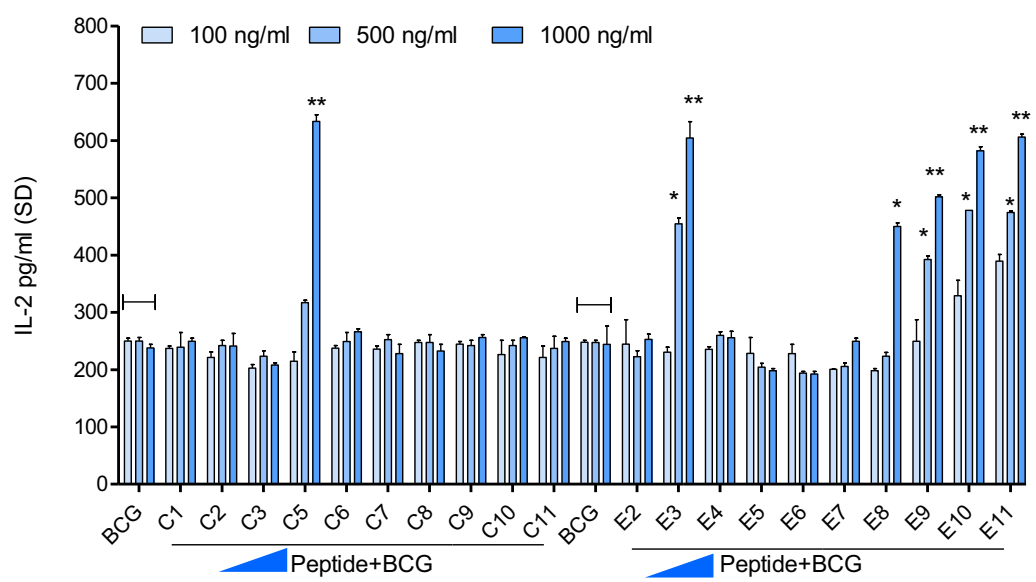

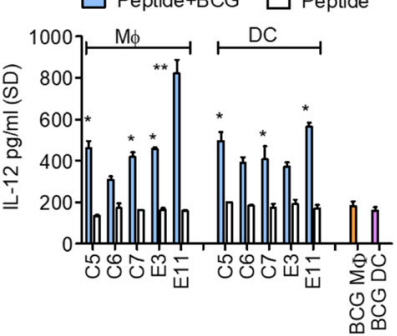
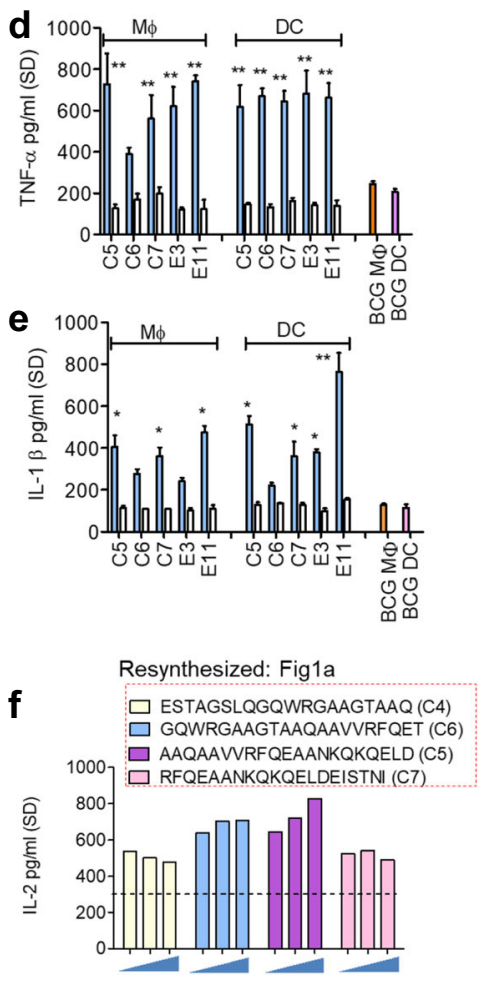

Fig. 2 CFP-10 and ESAT-6 proteins contain immune-enhancing peptides, which activate antigen-presenting cells in vitro. Synthetic peptides derived from CFP-10 and ESAT-6 proteins were tested for their ability to enhance Ag85B epitope presentation by BCG infected APCs to CD4 BB7 T cells in vitro. a, b Distinct peptide moieties of CFP-10 and ESAT-6 stimulate antigen presentation $(1000 \mathrm{ng} / \mathrm{mL}=0.5 \mu \mathrm{M})$. Values are pg/ $\mathrm{mL} \pm$ SD from triplicate wells. c-e The stimulatory peptides moieties derived from CFP-10 or ESAT-6 (each tested at indicates doses) were combined with BCG to infect APCs for assay of $T_{H} 1$ pro-inflammatory cytokines in the supernatants using ELISA. $f$ Peptides of CFP-10 were resynthesized to map " $\mathrm{C} 5$ " peptide which elicited maximal antigen presentation from MФs. All peptides of this panel show an increase in antigen presentation ( $p<0.009$ vs. BCG alone). Peptides were tested at indicates doses and dotted line represents IL-2 levels of BB7 T cells overlaid on BCG infected MФs $\left({ }^{*} p<0.01,{ }^{* *} p<0.003\right.$ vs. BCG alone control for all panels; one-way ANOVA with Dunnett's post test; one of two similar experiments shown for each panel)

combination and illustrated in Fig. 2c-e, infection of the knockout APCs elicited comparable cytokine responses, emphasizing the pivotal role of MyD88 and TLR-2 during antigen presentation (Fig. 3e, f).

Of the three TSPs evaluated in the preceding studies (C5, E3, and E11), C5 peptide from CFP-10 was the most potent in enhancing in vitro Ag85B presentation (Fig. 2a, b) and inducing cytokine secretion (Fig. 2c-e), and was thus selected for additional studies. TLR-1/2 and TLR-2/6 signaling leads to the activation of IRAK-4/1 and TRAF-6, which in turn activates downstream MAP kinases (MAPK) and NF-kB (Supplementary Fig. S3). ${ }^{42}$ Phosphorylated MAPKs or activated p65 then activate AP-I and/or CREB transcription elements, which translocate to the nucleus. These events induce pro-inflammatory cytokine secretion and MHC-II production, which are essential for peptide epitope presentation to CD4 T cells. To confirm signaling through this pathway, MФs were first infected with BCG with or without C5 peptide and lysates collected at intervals and analyzed using western blots.
Figure $3 g$ illustrates that C5 combined with BCG induced a stronger phosphorylation of both p38 and p42/44 ERK, whereas JNK was less significantly affected. In the next experiment, MФs from $w t-\mathrm{C} 57 \mathrm{BI} / 6$ and TLR-2-KO mice were activated first with $\mathrm{C} 5$ or E3 peptide or non-stimulatory peptides from the $\mathrm{N}$-terminus of CFP-10 protein (designated as C1, C2, and C3) for $4 \mathrm{~h}$ followed by BCG infection for $90 \mathrm{~min}$, and lysates examined for phosphorylation. Quantitation of the blots confirmed that a combination of BCG with C5 enhanced the phosphorylation of p38 and ERK in wtMФs, which was reduced in TLR-2-KO MФs (Fig. 3h, i).

C5 enhanced surface expression of MHC-II in APCs is dependent on MAPK and AP-1/CREB

BCG vaccine suppresses expression of MHC-II in phagocytic cells through the $19-\mathrm{kDa}$ lipoprotein. ${ }^{43}$ Mycobacterial peptide loaded MHC-II is critical for activation of CD4 T cells, and we reported earlier that BCG-derived Ag85B peptide is less efficiently 
a

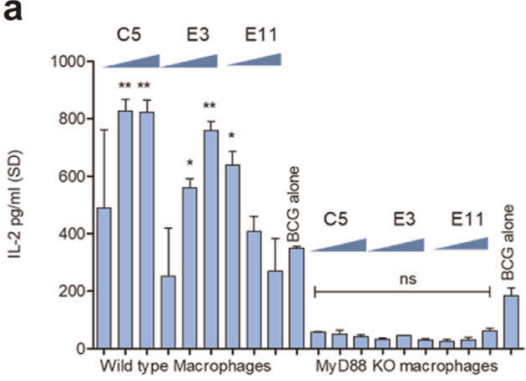

d

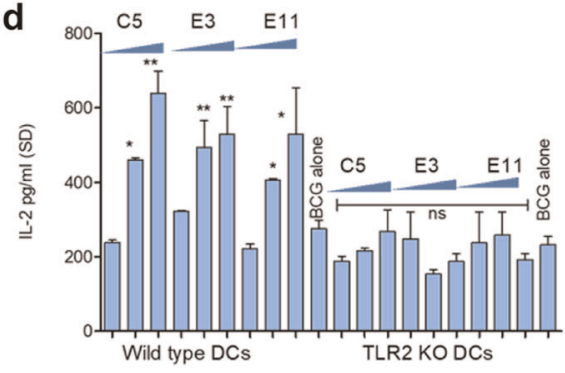

g
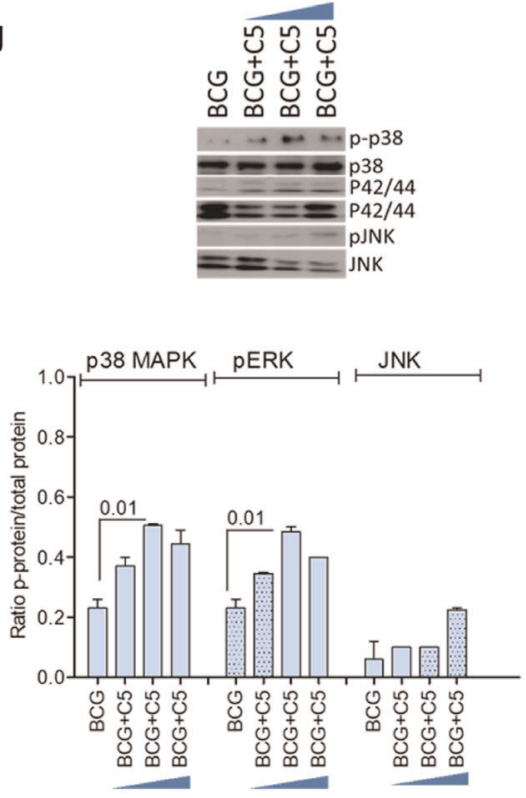

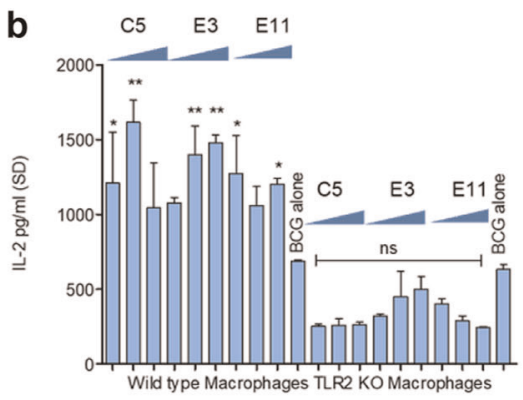

e

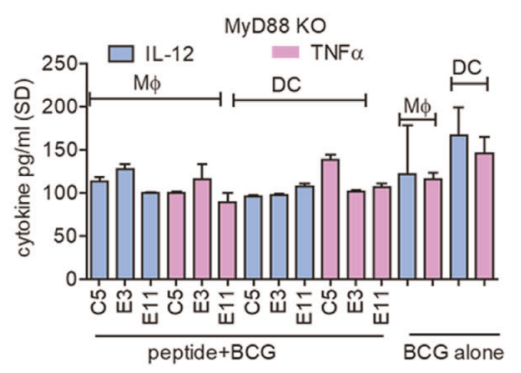

h
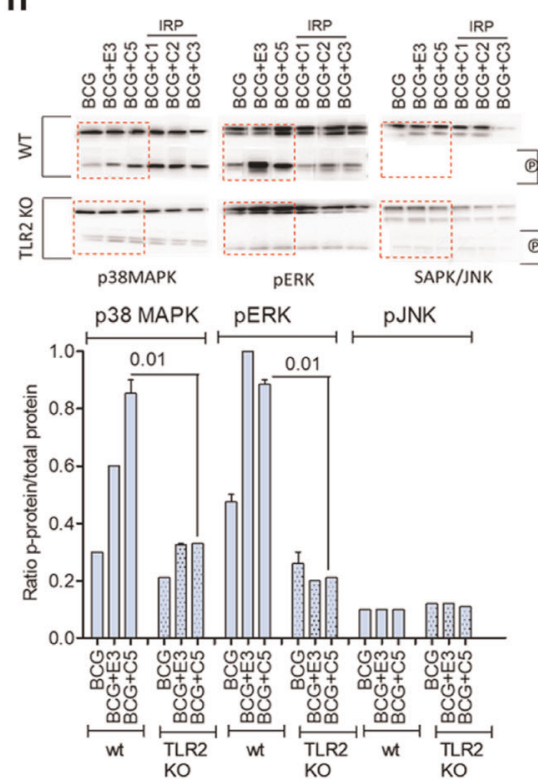

C

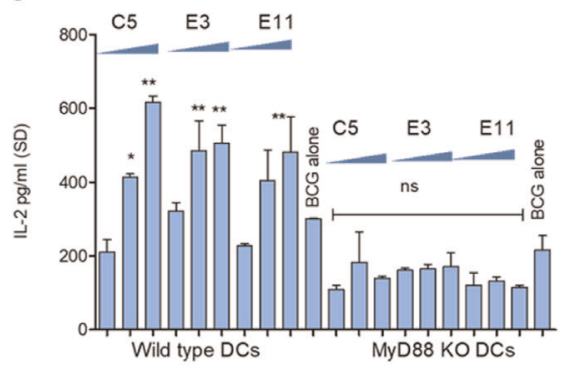

f

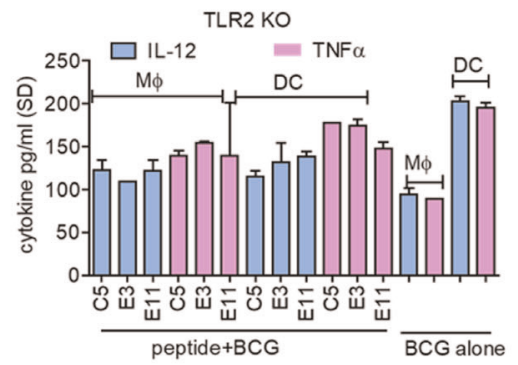

i
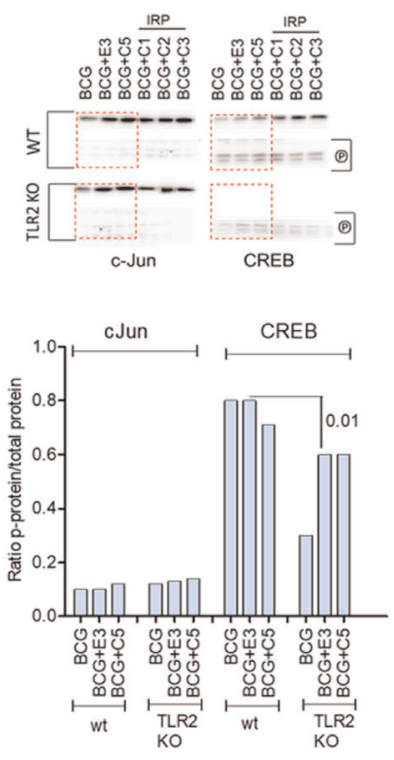

Fig. 3 CFP-10 and ESAT-6-derived peptides activate APCs through MyD88 and TLR-2-dependent pathways. a-d APCs from wild-type C57BI/6, MyD88, or TLR-2-deficient mice were tested using in vitro antigen presentation (peptides tested at 0.5, 1 , and $2 \mu \mathrm{M}$; one of two similar experiments shown; values are mean of IL-2 concentration for triplicate wells; ${ }^{*} p<0.01,{ }^{* *} p<0.006$ vs. BCG alone; one-way ANOVA). IL-2 levels secreted by BB7 T cells overlaid on knockout APCs are not significantly different. e, $\mathbf{f}$ APCs were activated or not with C5 and BCG and $T_{H} 1$ cytokines measured using sandwich ELISA. IL-12, and TNF- $\alpha$ cytokine responses are comparable with peptide activation followed by BCG vaccine infection or BCG infection alone among MyD88 or TLR-2 deficient APCs. g MФs were infected with BCG or BCG with C5 peptide followed by western blot of lysates for phosphorylated MAPKs at $30 \mathrm{~min}$. Densitometry shows that BCG + C5 peptide induce a stronger phosphorylation of p38 and ERK compared with native MAPK. Upper lanes show phosphorylated proteins, and lower lanes indicate whole protein. One of two similar experiments averaged for densitometry ( $t$ test). $\mathbf{h}$, $\mathbf{i}$ MФs from wild-type and TLR-2 knockout mice were incubated $4 \mathrm{~h}$ with C5 or E3 peptide or non-immunogenic peptides from CFP-10 protein followed by BCG infection for 90 min, followed by lysis and western blot assay for phosphorylated (P) MAPKs or C-Jun/AP-1 and CREB transcription factors. Densitometry (shown below blots) indicate that C5 peptide induces better phosphorylation in the presence of TLR-2 (phosphorylated bands marked (p); upper lanes have native proteins). One of two similar experiments is shown, which were averaged for densitometry ( $t$ test)

processed and presented to CD4 $\mathrm{T}$ cells by mouse MФs. ${ }^{13}$ Although MФs and DCs subtly differ in their ability to upregulate MHC-II, a common mechanism of upregulation of MHC-II is via the binding of the AP-1/CREB to the Class-II transactivator (CIITA) enhanceosome. ${ }^{44,45}$ To determine if $\mathrm{C} 5$ peptide affected antigen presentation through altering the levels of MHC-II, APCs were incubated with the inhibitors of MAPKs and AP-1/CREB, activated with $\mathrm{C} 5$ peptide followed by BCG infection and surface stained for MHC-II, before flow-cytometric analysis, as described before. ${ }^{46}$ Figure $4 \mathrm{a}$ indicates that $\mathrm{C5}$ added to the BCG vaccine enhanced 
a

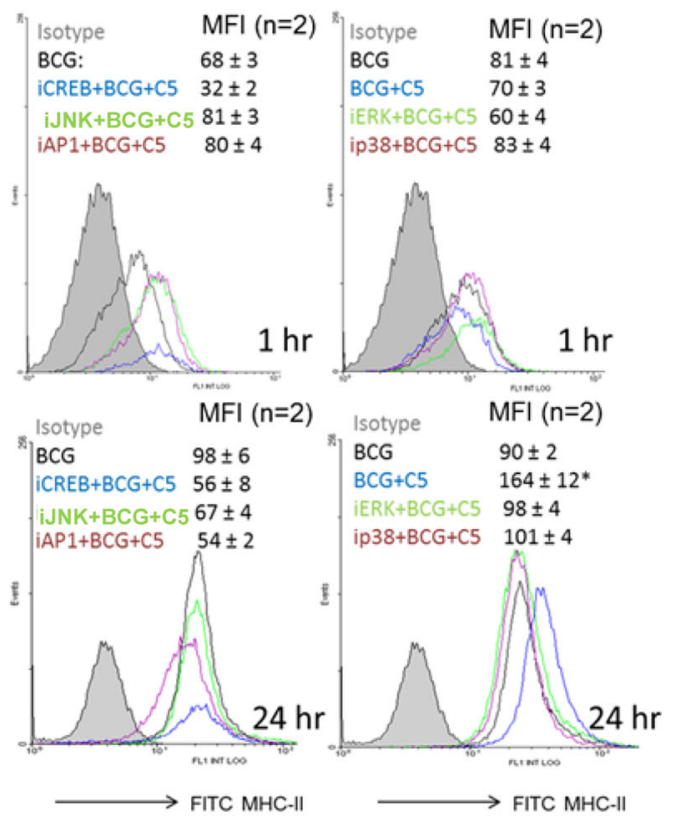

C

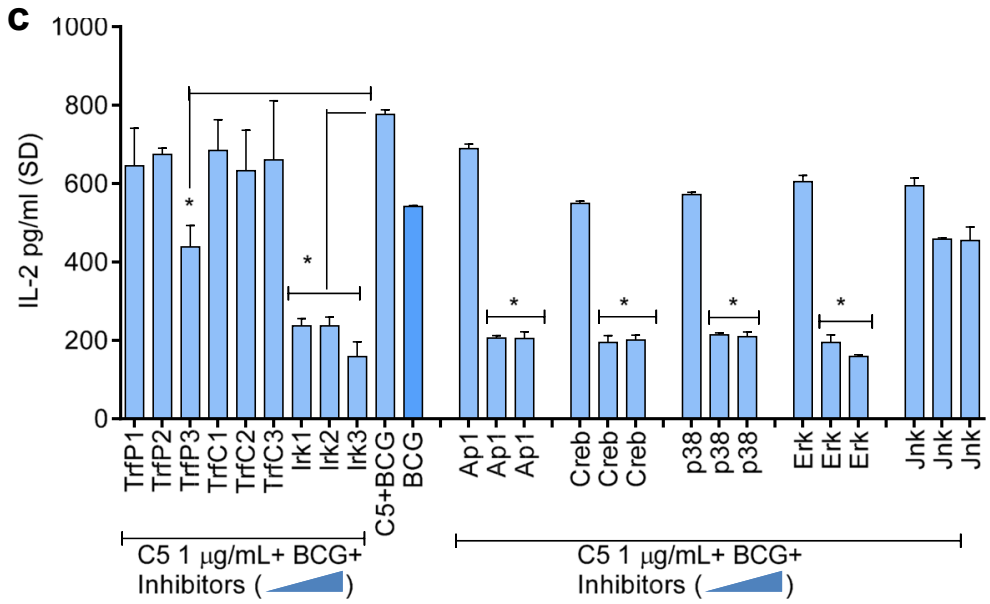

b
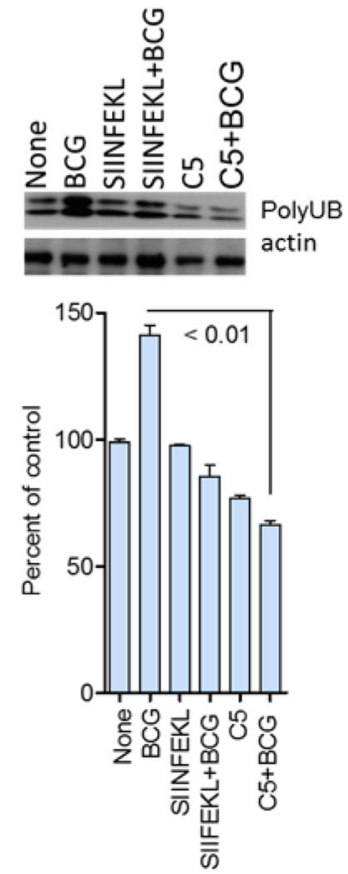

Fig. 4 CFP-10-derived C5 peptide induces an upregulation of MHC-II in MФs. a MФs from wild-type C57BI/6 mice were tested for surface expression of MHC-II. They were treated or not with $5 \mu \mathrm{M}$ of inhibitors of API/CREB and MAPK, followed by $2 \mathrm{~h}$ activation with C5 peptide, and 1 or $24 \mathrm{~h}$ infection with BCG, followed by MHC-II staining and flow cytometry. Inset numbers indicate mean fluorescence intensity (MFI) values averaged from two experiments ( \pm SD). C5 peptide enhances MHC-II expression in BCG-infected APCs and blockade of MAPK, AP-1/CREB reduces the levels of MHC-II ( ${ }^{*} p<0.01 ;$ BCG + C5 group vs. inhibitors). b MФs were tested naive or activated with C5 ( 2 h) and BCG ( 90 min) or irrelevant control SIINFEKL ova-peptide followed by BCG. Cell lysates prepared $4 \mathrm{~h}$ later were immune-precipitated with an antibody to MHC-II followed by probing with an antibody for ubiquitinated MHC-II. Densitometry (shown below) indicates that C5 activation decreases the levels

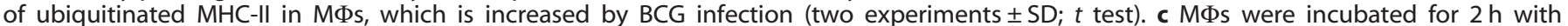
increasing doses of $(0.5,1$, and $2 \mu \mathrm{M}=$ lanes $1,2,3)$ specific (TrfP) or control (TrfP) peptide inhibitors of TRAF1/6; a peptide inhibitor of IRAK1/4 $($ IR1, 2, 3); peptide inhibitors of MAPKs; AP-1 and CREB and NF-kB (NF-tp, specific inhibitor; NF-cp, control peptide), followed by BCG or BCG + $\mathrm{C} 5$ for $2 \mathrm{~h}$. Washed monolayers were overlaid with Ag85B-specific CD4 BB7 T cells, and IL-2 in the supernatant was measured after $18 \mathrm{~h}$. Signaling blockade reduces antigen presentation by infected MФs ( ${ }^{*} p<0.009$ vs. BCG alone; one-way ANOVA with Dunnett's post test; one of two similar experiments shown)

MHC-Il expression over time in MФs, which was significantly reduced when either MAPK or AP-1/CREB was inhibited. One mechanism that targets MHC-II for degradation is its ubiquitination through the enzyme MARCH $1 .{ }^{46}$ To determine if $\mathrm{C} 5$ induced increase in MHC-II is due to prevention of its degradation, lysates of $M \Phi$ s treated with $C 5$ and $B C G$ or a control (ovalbumin-derived) SINFEKL peptide with BCG were tested for ubiquitinated MHC-II using western blots as described. ${ }^{46}$ Figure $4 \mathrm{~b}$ shows that $\mathrm{C} 5$ combination with BCG reduced the levels of ubiquitinated MHC-II compared with the control peptide. Since the latter is targeted for degradation through proteasomes, we propose that activation of MФs with C5 peptide helps to maintain adequate levels of MHC-II for antigen presentation. ${ }^{47}$ Additional studies showed that $\mathrm{C5}$ combination with BCG enhances MHC-II expression in DCs while, signaling inhibitors alone had no suppressive effect on BCG infected APCs (Supplementary Fig. S4). To further confirm the role of the signaling pathway that regulated MHC-II during antigen presentation, MФs were incubated with specific and control peptide inhibitors of TRAF- 6 and NF-kB; a specific peptide inhibitor of IRAK-4/1, and a previously validated set of known inhibitors of 


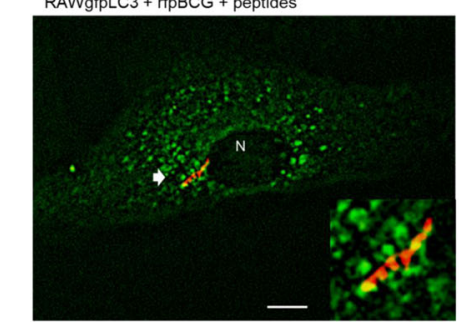

b

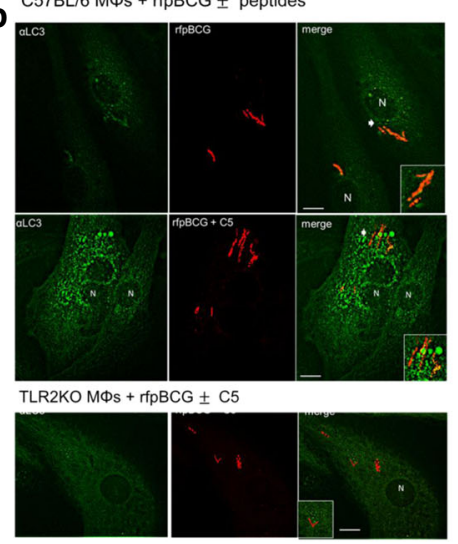

C
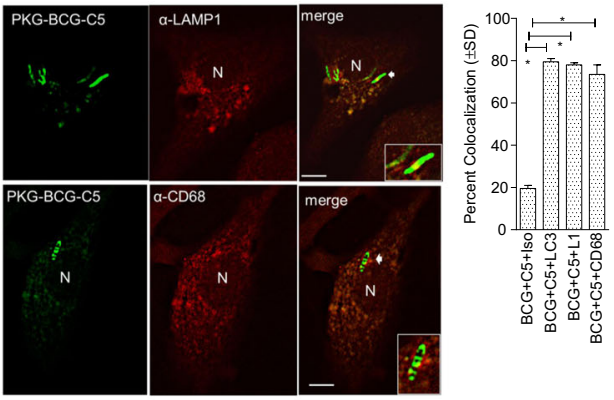

d

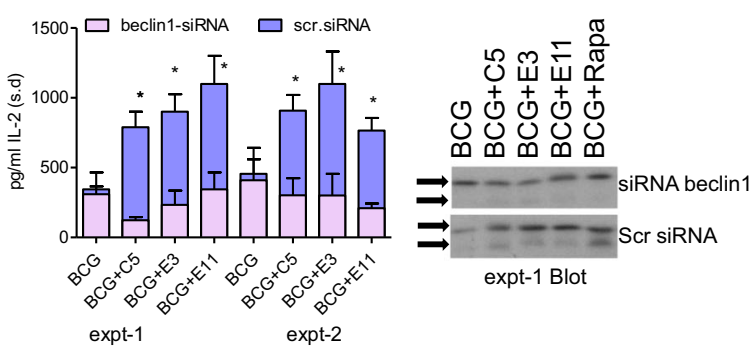

Fig. 5 TLR-2 stimulating CFP-10-derived C5 peptide enhances autophagy in MФs through LC3 binding. a, b RAW.A4 MФs transfected with gfpLC3 were activated or not with TLR-2 stimulating peptides (TSPs) $(1 \mu \mathrm{g} / \mathrm{mL}$ for $4 \mathrm{~h}$ ), and infected with $r f p-B C G$ and washed. Likewise, primary МФs from either wt-C57Bl6 mice or TLR-2-KO mice were infected with $r f p$-BCG with or without TSPs, washed, fixed, and stained using antibodies to LC3 and imaged using confocal microscopy. Percent autophagosomes colocalizing with BCG were calculated from three separate experiments and plotted $\left({ }^{*} p<0.009\right)$. rfp-BCG did not colocalize with LC 3 in TLR-2 KO MФs. C5 peptide alone had no effect on the numbers of autophagic puncta (not shown). c wt-C57BI/6 MФs were infected as above and stained for lysosome markers LAMP1 and CD68 followed by quantitation of labeling. $\mathbf{d} M \Phi$ s were either treated or not with siRNA vs. beclin 1 to selectively block autophagy and scrambled siRNA as control, followed by infection with wt-BCG, or its combination with C5 peptide at a dose $(1 \mu \mathrm{g} / \mathrm{mL} ; 0.5 \mu \mathrm{M}) \mathrm{known}$ to enhance antigen presentation. BB7 CD4 T cells were overlaid on the MФs, and IL-2 determined using sandwich ELISA. When autophagy was not blocked (blue fill), TSPs combined with BCG increased antigen presentation. When autophagy was inhibited using siRNA beclin1 (purple fill) antigen presentation was decreased $\left({ }^{*} p<0.01\right.$ vs. scrambled siRNA control; two experiments, $\left.\pm \mathrm{SD}\right)$. $P$-values were determined using one-way ANOVA with Dunnett's post test. e Lysates of MФs from one of the ELISA experiments were analyzed using an antibody to LC3; they show reduced lipidation of LC3 bands after siRNA vs. beclin1 treatment

MAPK, C-jun AP-1, and CREB. ${ }^{46}$ MФs were then activated with C5 peptide, followed by infection with BCG and antigen presentation. Antigen presentation was significantly reduced when these effectors were blocked with the exception of JNK, consistent with the profile of kinase phosphorylation from western blot data (Fig. $3 g-h)$. It should be noted here that, lipoproteins and lipids of mycobacteria (19 kDa and LprG lipoproteins; lipoarabinomannan, LAM) cause multiple, mostly immuno-suppressive effects on APCs through TLR-2 and TLR-4-dependent pathways. ${ }^{43,48,49}$ Data shown above suggest that the $C 5$ expressed by BCG can counteract the effects of these suppressive lipoproteins.

C5 induces autophagy in MФs increasing lysosomal delivery of the $B C G$ vaccine and increasing antigen presentation

BCG is an interesting live attenuated vaccine that sequesters in immature phagosomes of $\mathrm{M \Phi s}$, and we demonstrated earlier that maturation arrest interferes with antigen presentation. ${ }^{13}$ Thus, MФs infected with BCG were less able to present the p25 epitope from Ag85B to CD4 cell hybridoma in vitro. ${ }^{13}$ On the other hand, we demonstrated that rapamycin-induced autophagy in BCGinfected $M \Phi$ s and DCs increased antigen presentation to CD4 T cells. ${ }^{14}$ Interestingly, TLR-2 ligands are known to facilitate a unique type of uptake and lysosomal localization of particulate antigens involving the microtubule-associated light chain-3 (LC3), which is also a marker of the autophagosome. ${ }^{50,51}$ To determine whether C5 peptide induced TLR-2 activation and enhanced LC3 labeling and thus autophagy, RAW-MФs transfected with $g f p L C 3$ were infected with rfp-tagged BCG mixed with C5, E3, and E11 peptides. Following phagocytosis and wash, LC3 colocalization was evaluated using the Nikon metaview software. Figure 5a illustrates that $C 5$ peptide markedly enhanced the colocalization of $g f p L C 3$ with $r f p$-BCG. Since RAW-MФs are from BALB/c mice, and not suitable to demonstrate a correlation between autophagy and antigen presentation, in the next experiment, C57BI/ 6 mouse bone marrow-derived primary MФs were then infected with $r f p$ BCG mixed with TSPs, incubated for $24 \mathrm{~h}$ and stained for LC3 using antibodies and FITC-anti lgG conjugates. Figure $5 \mathrm{~b}$ shows that $r f p$ BCG mixed with the TSPs showed enhanced labeling with LC3 confirming autophagosome formation. Interestingly, MФs derived from TLR-2 KO mice showed poor staining of LC3 on rfp-BCG phagosomes, suggesting that $\mathrm{C} 5$ induced autophagy through TLR2. Finally, C5 enhanced the colocalization of gfpBCG phagosomes with LAMP1 and CD68, which are two markers of lysosomes (Fig. 5c).

TLR-2 activation initiates a unique kind of LC3-dependent autophagy among mouse and human APCs, facilitating an MHC-IIdependent antigen presentation. ${ }^{50,51}$ Since C5 peptide enhanced LC3 labeling and lysosomal localization through TLR-2, wt-MФs were treated with siRNA vs. beclin1 to knockdown autophagy, infected with BCG with or without C5 peptide and antigen presentation was evaluated. Figure $5 \mathrm{~d}$ illustrates that siRNA KO significantly decreased antigen presentation even when BCG was treated with $C 5$ peptide. In addition, the lysates of such MФs were found to have decreased lipidation of LC3 confirming autophagy 
knockdown (Fig. 5e). These data together support the observation that C5 peptide enhances autophagy and lysosomal localization for BCG vaccine, thereby increasing the MHC-II-dependent presentation of Ag85B-derived peptide.

\section{C5 peptide mixed with BCG protects against aerosol-induced} tuberculosis in mice

Since C5 peptide enhanced in vitro immunogenicity of BCGinfected MФs, we sought to determine its in vivo effect. A series of CFP-10 peptides including C5 and selected ESAT-6-derived peptides were mixed with BCG, and mice were vaccinated followed by aerosol challenge with Mtb. The data show that among the CFP-10 peptides, only C5 enhanced the protective efficacy of BCG vaccine when given at as two small doses with BCG (Supplementary Fig. S5). In contrast, among ESAT-6-derived peptides, E1 and E2 nullified the effect of BCG while E3, E10, and E11 had no significant booster effect on BCG. These observations correlate with the ability of ESAT-6 to inhibit MHC-II expression in MФs and T-cell responses. ${ }^{27,52}$

\section{Genetic engineering of TLR-2 stimulating peptide C5 into BCG} vaccine and validation

The data presented above indicated that the $C 5$ peptide exerted a novel "adjuvant-action" on BCG infected APCs, which translated into increase in the efficacy of CFP-10 peptides mixed with BCG vaccine. C5 was also superior to E3 and E11 peptides (Supplementary Fig. S5). We reported earlier that, overexpression of $\mathrm{Ag} 85 \mathrm{~B}$ in BCG Pasteur (creating $\mathrm{BCG}^{85 \mathrm{~B}}$; aka. rBCG30) enables secretion of $\mathrm{Ag} 85 \mathrm{~B}$ in copious quantities, which induces aggresome-dependent autophagy and enhances efficacy against tuberculosis in mice. ${ }^{14}$ Since $r B C G 30\left(=B_{C G}{ }^{85 B}\right)$ has undergone human trials, and could potentially replace $w t-\mathrm{BCG}^{53,54}$; we sought to further increase the efficacy of the $B_{C G}{ }^{85 B}$ vaccine through expression of $\mathrm{C} 5$ peptide.

C5 peptide was expressed (methods) as a part of secreted $A g 85 B$ of $B C G^{85 B}$ vaccine yielding $B C G^{85 C 5}$. For comparison, the whole CFP-10 protein was expressed along with Ag85B yielding $\mathrm{BCG}^{85 C F P}$. In vitro antigen presentation studies confirmed that $\mathrm{BCG}^{85 C 5}$ showed stronger and sustained antigen presentation in mouse DCs over 5 days compared with wt-BCG (Supplementary Fig. S6). Importantly, BCG ${ }^{85 C 5}$ elicited an Ag85B epitope presentation to CD4 T cells from human cord blood-derived MФs, which was significantly decreased after TLR-2 receptor knockdown (Supplementary Fig. S7). BCG ${ }^{85 C 5}$ elicited a robust reactive oxygen species response from wt-MФs, which decreased in TLR2R-KO MФs, confirming its ability to activate TLR-2 (Supplementary Fig. S8). BCG $^{85 C 5}$ also elicited a strong antigen presentation from bone marrow-derived DCs of wt-C57BI/6 mice, which was markedly decreased among DCs with a conditional knockout of atg7 on C57BI/6 background (Supplementary Fig. S9). Finally, when splenocytes from $B C G^{85 C 5}$ or other BCG strains were incubated in vitro with recombinant CFP-10 protein, only those from $B_{C G}{ }^{85 C 5}$ vaccinated mice elicited robust IFN- $\gamma$ response (Supplementary Fig. S10).

The parent $\mathrm{BCG}^{85 \mathrm{~B}}$ was then compared with $\mathrm{BCG}^{85 C 5}$ vaccine using wt- and TLR-2 KO mice to determine if TLR-2 was required for the efficacy of $\mathrm{BCG}^{85 \mathrm{C} 5}$ against tuberculosis challenge of mice. In a second and expanded study, wt-C57BI/6 mice were used to compare the efficacy of $B_{C} G^{85 C 5}$ with $B^{2} G^{85 C F P}$ for memory T-cell responses and protection against tuberculosis. It should be noted here that both these constructs overexpress Ag85B.

$B C G^{85 C 5}$ vaccine requires TLR-2 for better vaccine efficacy in mice compared with wt-BCG or BCG ${ }^{85 B}$ vaccine

In the well-established $\mathrm{NIH}$ mouse model of tuberculosis vaccine evaluation, wt-BCG protects against aerosol-induced tuberculosis reducing the lung colony (CFU) counts of Mtb by a $\log _{10} 4$ weeks after challenge. ${ }^{55}$

Post-vaccination immune responses. The NIH mouse model with $w t-C 57 \mathrm{BI} / 6$ and TLR-2-KO mice were used to compare the efficacy of wt-BCG Pasteur with $\mathrm{BCG}^{85 \mathrm{~B}}$ and $\mathrm{BCG}^{85 \mathrm{C} 5}$ (Fig. 6a). To ascertain immunogenicity of the vaccines, 21 days after vaccination, mice were killed and splenocytes analyzed for MHC-II Ag85B-specific CD4 T cells (NIH core tetramer facility, Emory University, Methods) and in vitro recall immune responses to antigens. ${ }^{56}$ The data show that, $\mathrm{BCG}^{85 \mathrm{C} 5}$ induced a twofold expansion of antigen-85B-specific CD4 T-cell responses post vaccination among $w t-C 57 \mathrm{BI} / 6 \mathrm{com}-$ pared with TLR-2-KO mice (Fig. $6 \mathrm{~b}-\mathrm{c}$ ). In addition, IFN- $\gamma$ levels of the supernatants of splenocytes activated with four individual antigens confirmed that $\mathrm{BCG}^{85 \mathrm{C5}}$ vaccinated T cells from wt-C57BI/ 6 showed twofold stronger recall responses (Fig. $6 \mathrm{~d}$ ). The antigens were selected such that recall responses could occur in a specific manner; thus, Ag85B was present in both BCG and Mtb whereas ESAT- 6 and CFP-10 were absent in BCG and present in Mtb. Figure $6 \mathrm{~d}$ for example, illustrates that, CFP-10 elicited IFN- $\gamma$ recall responses in splenocytes of mice given only $\mathrm{BCG}^{85 C 5}$, but not those given either wt-BCG or $\mathrm{BCG}^{85 \mathrm{~B}}$. These data support the observation that $\mathrm{BCG}^{85 \mathrm{C} 5}$ enhances both in vitro and in vivo antigen presentation and expands Ag85B-specific CD4 T cells.

Post-aerosol challenge immune responses. Since the specificity and immunogenicity of $\mathrm{BCG}^{85 \mathrm{C} 5}$ was established, wt-C57BI/6 mice and TLR-2-KO mice were used to evaluate vaccine efficacy. Protection against tuberculosis challenge was correlated with levels of CD4 and CD8 T cells important for defense against tuberculosis. Figure 6e illustrates that $\mathrm{BCG}^{85 \mathrm{C} 5}$ generated better protection than wt-BCG or $\mathrm{BCG}^{85 \mathrm{~B}}$ vaccine in the lungs and spleens of $w t-C 57 B L / 6$ mice. Interestingly, protection generated by $\mathrm{BCG}^{85 C 5}$ was significantly reduced in the organs of TLR-2-KO mice, underscoring the importance of TLR-2 (Fig. 6f). BCG ${ }^{85 B}$ induces robust CD4 and CD8 T-cell responses in mice. ${ }^{14}$ To determine the antigen specificity of BCG-induced $T$ cells mediating protection against tuberculosis, $T$ cells were phenotyped using three wellcharacterized CD8 tetramers along with an MHC-II tetramer for Ag85B (NIH core tetramer facility, Emory University, USA). Of these, TB10.4 antigen elicits robust response in mice. BCG ${ }^{85 C 5}$ induced significantly higher levels of IFN- $\gamma^{+}$CD8 T cells specific for TB10.4 antigen of Mtb in the lungs (Fig. 6g; Histograms illustrated in Supplementary Fig. S11). Both TB10.4 and other antigen-specific CD8 T cells were reduced in the lungs of TLR-2-KO mice (Fig. $6 \mathrm{~h}$ ). Bead purified CD8 T cells from the lungs of these mice were then evaluated for ability to kill Mtb in vitro, and they were functionally active (Fig. 6i). Since TB10.4 ${ }^{+}$CD8 T cells are associated with protection against tuberculosis in mice, these data confirm the superior efficacy of $\mathrm{BCG}^{85 \mathrm{C} 5}$ and its dependence on TLR-2. ${ }^{57}$ Finally, the lungs of vaccinated mice contained elevated levels of Ag85B-specific CD4 T cells and MFCs (Fig. 6j, k). These data are consistent with the observation that both Mtb infection and BCG vaccination expand Ag85B-specific CD4 T cells in vivo, and unlike $w t-B C G, B^{85 C 5}$ induces better responses of MFCs in mice. ${ }^{56,58,59}$

Primary and reinfection tuberculosis models in wt-C57BI/6 mice to measure the expansion of $T_{E M}$ effector and $T_{C M}$ memory $T$ cells correlating with protection

The BCG vaccine induces significant CD4, but reduced CD8 cell responses in mice which correlates with short-term protection against tuberculosis in mice. ${ }^{60}$ T cells expressing memory markers have been demonstrated in the lungs of mice following BCG vaccination. ${ }^{61}$ Some investigators have suggested that decreased long-term protection in mice could be due to the lack of cells mediating central memory. ${ }^{62}$ Using a mouse reinfection model of tuberculosis, CD4 T cells expressing memory phenotype were 
a

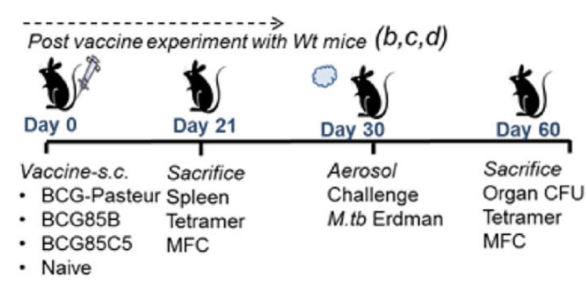

b

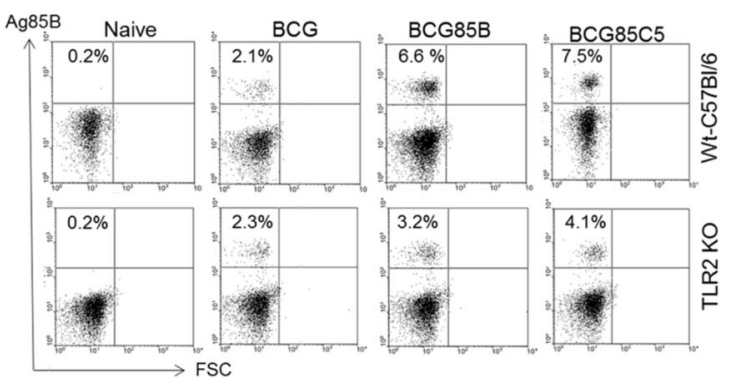

C

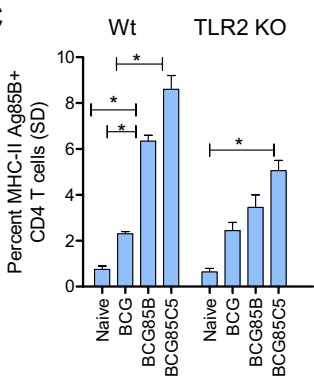

e

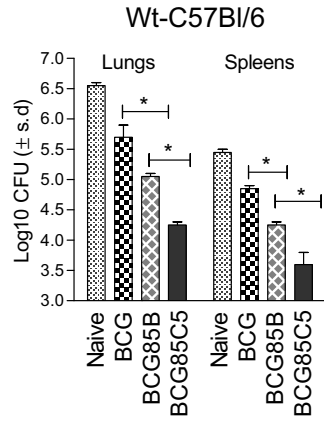

d

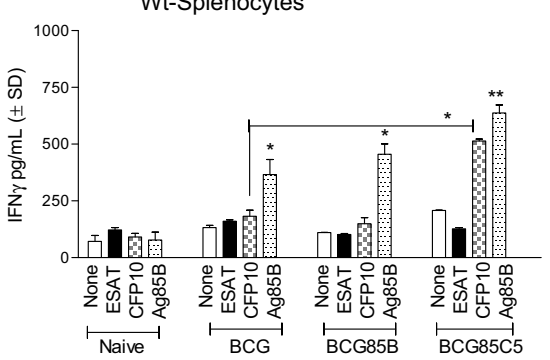

TLR2KO-Splenocytes

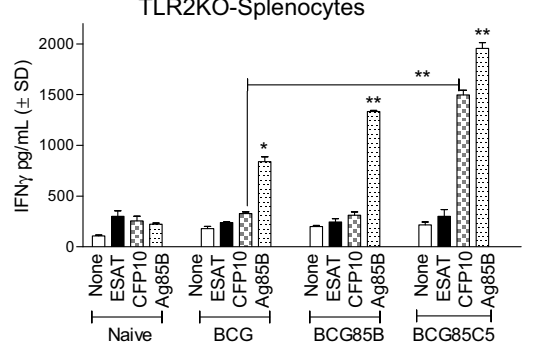

9 Wt-C57BI/6 Lungs CD8 T cells

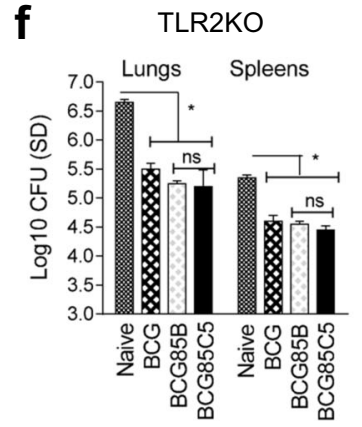

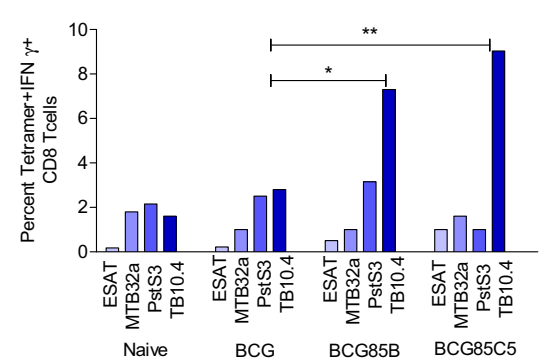
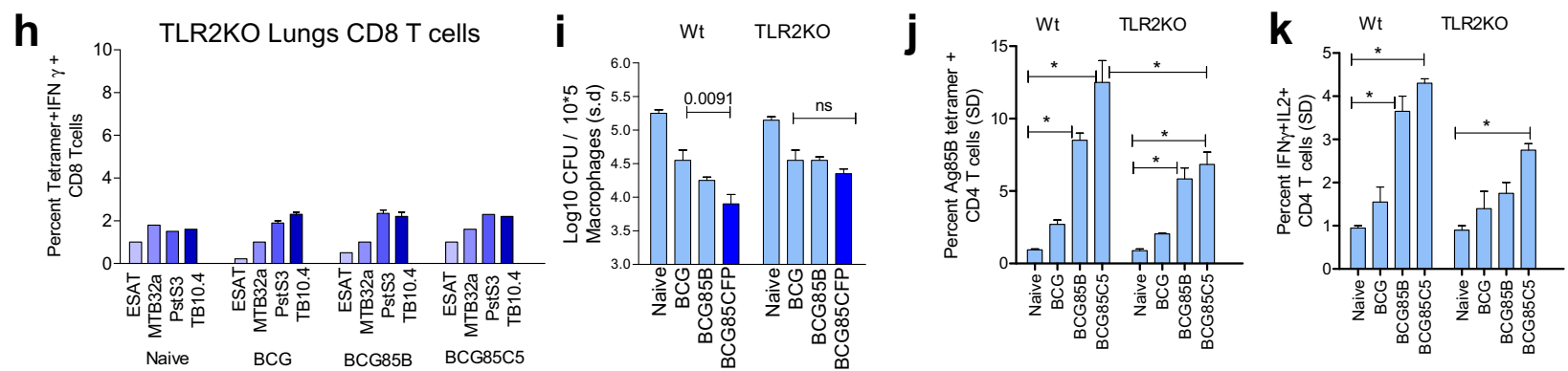

Fig. 6 Recombinant BCG vaccine expressing Ag85B and C5 peptide (BCG $\left.{ }^{85 C 5}\right)$ induces TLR-2-dependent protection against aerosol-induced tuberculosis of mice. a NIH short-term BCG vaccine induced protection mouse model. C57BI/6 mice (4-6 weeks M/F) were vaccinated as indicated with BCG strains or left untreated (naive); followed by aerosol challenge with 100 CFU per mouse of virulent M. tuberculosis Erdman (Mtb) and killed for bacterial (CFU) counts of lungs and spleens and for T-ell assays. b, c Splenocytes on day 21 were stained using Ag85BMHC-II tetramer (NIH tetramer core; Emory University) for CD4 T cells. The data averaged for three mice; $t$ test. $\mathbf{d}$ Splenocytes were cultured with soluble antigens $\left(5 \mu \mathrm{g} / \mathrm{mL}\right.$ ) as indicated for $18 \mathrm{~h}$ and IFN- $\gamma$ ELISA. The data averaged for three mice per group (mean \pm SD; ${ }^{*} p<0.01$; ${ }^{* *} p<$ 0.0071 ; one-way ANOVA). e, f On day 60 , organs were harvested for Mtb counts. BCG ${ }^{85 C 5}$ yields better protection than wt-BCG and BCG ${ }^{85}$ in reducing the load of Mtb in the lungs and spleens of wild-type mice. Protection generated by BCG ${ }^{85 C 5}$ is significantly reduced in TLR-2 knockout mice ( ${ }^{*} p<0.0091$; two-way ANOVA; $n=5$ mice per group and vaccine). $\mathbf{g}$, $\mathbf{h}$ Lung T cells of wild-type and TLR-2 knockout mice on day 60 ( $n=3$ per group) were analyzed with flow cytometry using tetramers specific for MHC-I type epitopes from ESAT-6, Mtb32a, PstS3, and TB10.4 antigens of Mtb (histograms illustrated in Supplementary Fig. S11) (see the Methods section). Cells were gated on CD8, intracellular IFN- $\gamma$ and MHC class-I tetramers. BCG ${ }^{85 C 5}$ induces a stronger expansion of antigen-specific tetramer-positive CD8 T cells in wild-type mice compared to TLR-2 knockout mice $\left({ }^{*} p<0.01\right.$; one-way ANOVA). i Purified CD8 T-cell pools from lungs of vaccinated or naive mice ( $n=3$ per group) were overlaid on Mtb infected macrophage monolayers followed by CFU counts at $72 \mathrm{~h}$ ( $p$-values, vaccine groups vs. naive; one-way ANOVA). $\mathbf{j}$, $\mathbf{k}$ Lung T cells of mice collected on day 60 ( $n=3$ per group) were stained using Ag85B-specific MHC-Il tetramer and for multifunctional cytokine secreting CD4 T cells (MFCs) $\left({ }^{*} p<0.01\right)$. P-values were determined using one- or two-way ANOVA with Dunnett's post-test 
a

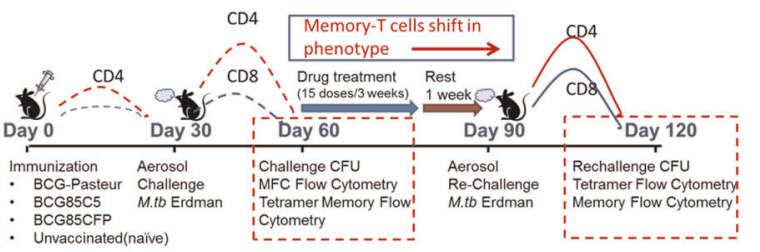

b
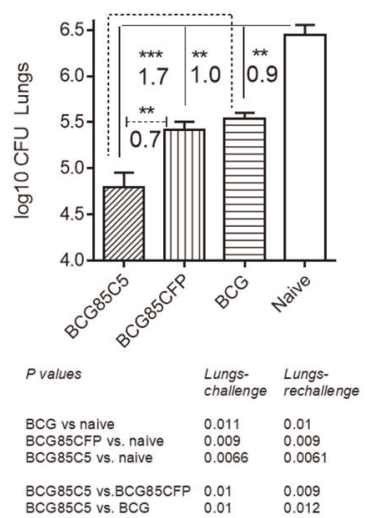

f
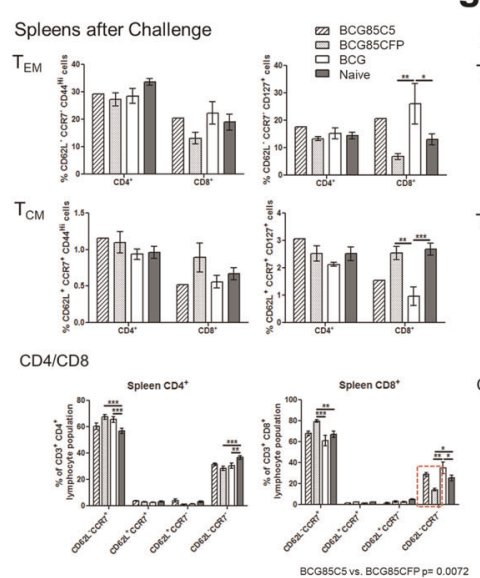
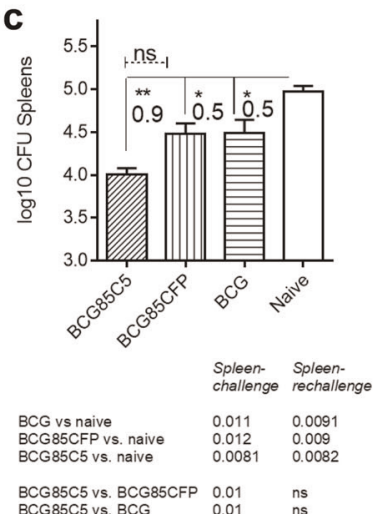

g d

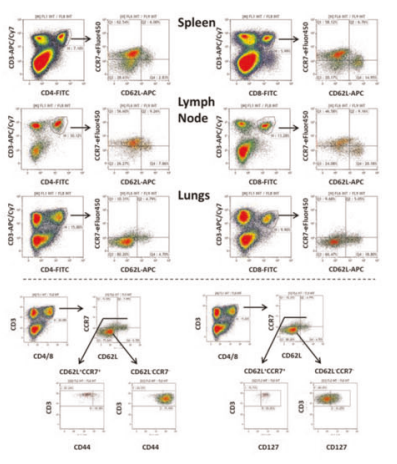

e
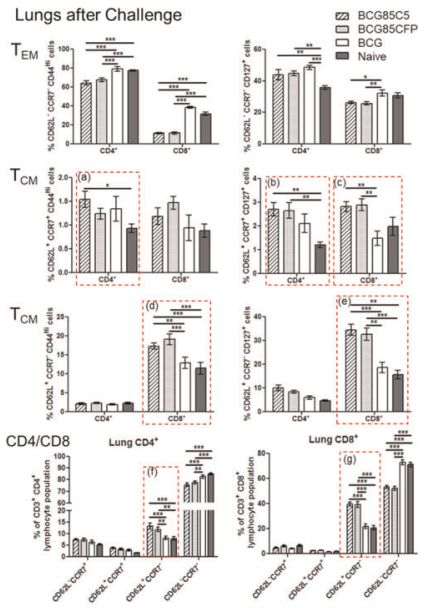

h
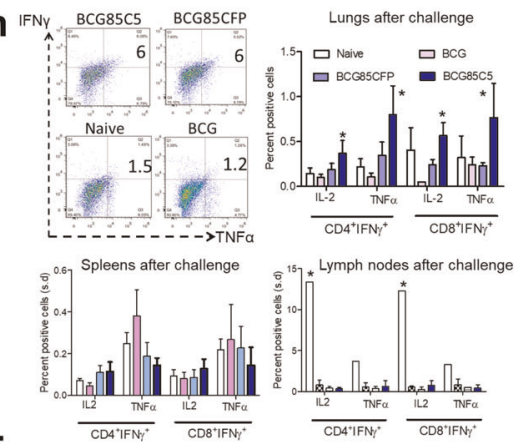

i
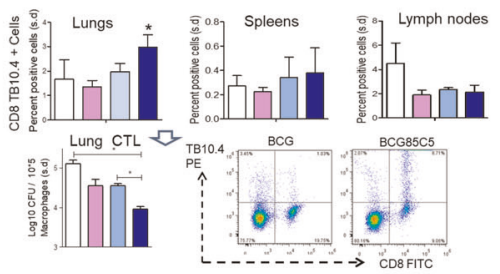

Fig. $7 \quad \mathrm{BCG}^{85 C 5}$ vaccine induces a robust protection against primary challenge of tuberculosis in mice through effector ( $\left.T_{E M}\right)$ and central memory $\left(\mathrm{T}_{\mathrm{CM}}\right) \mathrm{T}$ cells. a NIH short-term protection (Fig. $6 \mathrm{a}$ ) and a long-term protection (rechallenge) models are shown. Rechallenged mice were vaccinated, treated with isoniazid and rifampin (mix of $10 \mathrm{mg} / \mathrm{kg}$ dose each), rested and challenged with $\mathrm{Mtb}$. The data for $\mathrm{NIH}$ and rechallenge models are shown in Fig. 7 and Fig. 8, respectively. Post-vaccine mice were killed on day 21, post challenge on day 60 and post rechallenge mice on day 120 . Post vaccination Ag85B-specific T cell analysis in Supplementary Fig. S10. b, c CFU counts of Mtb in the lungs and spleens after primary challenge (day 60 ). BCG $^{85 C 5}$ reduces Mtb CFUs (mean \pm SD) of lungs and spleens better than BCG. $P$-values and $\log 10$ difference of CFUs indicated (footnote; $n=5$ mice per group; two-way ANOVA). $\mathbf{d}$ Histogram analysis of T cells for memory markers using flow cytometry. e-g $B C G^{85 C 5}$ induces both $T_{E M}$ and $T_{C M} T$ cells in the lungs after primary challenge. Vaccine groups with significant differences in memory populations are highlighted $\left({ }^{*} p<0.02 ;{ }^{* *} p<0.01 ;{ }^{* * *} p<0.008\right.$; one-way ANOVA). BCG ${ }^{85 C 5}$, BCG $^{85 C F P}$ and wt-BCG induce comparable numbers of $\mathrm{T}_{\mathrm{EM}}$ in lungs, spleens, and lymph nodes, while, $B C \mathrm{G}^{85} \mathrm{C}^{5}$ and $B C G^{85} \mathrm{CF}$ induce better $\mathrm{T}_{C M}$ than wt-BCG in the target organ lungs (Fig. 7e; p boxes a-e). CD4/CD8 panels (Fig. 7e, $\mathrm{f}, \mathrm{g}$ ) indicate percent of cells calculated after estimating absolute numbers $(n=3$ mice), which were then averaged. $\mathrm{BCG}^{85 C 5}$ increases absolute numbers of effector $\mathrm{CD}^{2} \mathrm{~L}^{-} \mathrm{CD} 4$ and $\mathrm{CD} 8 \mathrm{~T}$ cells in the lymph nodes compared with wt- BCG (vs. Fig. 7g; p boxes a, b) and effector CD62L ${ }^{-}$CD8 T cells in the spleens (vs. Fig. 7f). $\mathbf{h}$ BCG ${ }^{85 C 5}$ enhances levels of multifunctional cytokine secreting T cells of lungs ( ${ }^{*} p<0.01$; one-way ANOVA). i TB10.4 tetramer specific CD8 T cells of the lungs, spleens, and lymph nodes. Clockwise. TB10.4 ${ }^{+}$CD8 T cells in naive or vaccinated mice. Histogram of TB10.4 CD8 T cells. Purified CD8 pools $(n=3)$ of naive or vaccinated group, overlaid in vitro on Mtb-infected macrophages followed by CFU counts. ( ${ }^{*} p<0.009$; one-way ANOVA). P-values determined using oneor two-way ANOVA with Dunnett's post-test

found to generate a transient protection against tuberculosis. ${ }^{62}$ $\mathrm{BCG}^{85}$ vaccine mixed with $C 5$ peptide activated APCs to induce robust $\mathrm{TH} 1$ cytokines and antigen presentation to CD4 T cells in vitro through enhanced surface expression of MHC-II. Figure 6 confirmed that TLR-2 mediated activation of APCs translated well into better protection against aerosol-induced tuberculosis of mice. Thus, we sought to examine the ability of $\mathrm{BCG}^{85 \mathrm{C} 5}$ to generate $T_{E M}$ and $T_{C M}$ using an improved tuberculosis rechallenge mouse model. In this model illustrated in Fig. 7a, the first half represented the $\mathrm{NIH}$ model (primary challenge model), and the second half, allowed vaccine-induced $T_{E M}$ to expand in response to a challenge with tuberculosis, followed by a drug-induced cure of infection, and a resting period which facilitated the emergence $\mathrm{T}_{\mathrm{CM}} \cdot{ }^{55,57,63}$ Mice were then rechallenged with Mtb (aka. reinfection model) to determine whether $\mathrm{T}_{\mathrm{CM}}$ could protect against tuberculosis. 
Since $B C G^{85 C 5}$ was found superior to $B C G$ in Fig. 7, in this experiment $\mathrm{BCG}^{85 \mathrm{C} 5}$ was compared with $\mathrm{BCG}^{85 \mathrm{CFP}}$ and wt-BCG. Thus, wt-C57Bl/6 mice were vaccinated with wt-BCG, BCG ${ }^{85 C F P}$, and $B C G^{85 C 5}$ followed by aerosol infection at 4 weeks (day 60) (Fig. 7a). Post-vaccination and post-challenge immune responses were evaluated as in Fig. 7 and correlated with protection enumerating Mtb CFUs on day 60. A duplicate set of mice vaccinated and challenged as above were treated with drugs (Isoniazid and rifampin) to clear both vaccine and Mtb organisms, followed by a resting period and rechallenge with virulent Mtb on day 90 (Fig. 7a). Post-rechallenge immune responses were correlated with protection against reinfection ( $\log _{10}$ reduction in CFUs) determined by Mtb CFU counts 30 days after rechallenge (Fig. 7a). Several earlier studies assessing protection against viral and bacterial pathogens of the mouse model indicate that $\mathrm{T}_{\mathrm{EM}}$ cells are phenotypically $\mathrm{CD} 6 \mathrm{~L}^{-} \mathrm{CCR} 7 \mathrm{CD}^{-} 4^{\mathrm{hi}} \mathrm{CD} 127^{+/-}$whereas, $\mathrm{T}_{\mathrm{CM}}$ memory $\mathrm{T}$ cells are $\mathrm{CD} 62 \mathrm{~L}^{+} \mathrm{CCR} 7^{+/-} \mathrm{CD} 44^{\text {hi }} \mathrm{CD} 127^{+62,64-67}$ Based on receptor distribution, two additional subsets of $T_{E M}$ and four subsets of $T_{C M}$ were typed using vaccinated and naive mice with optimized markers and flow-cytometry data presented as percent distribution and absolute numbers of CD4 and CD8 memory $T$ cells per organ.

$B C G^{85 C 5}$ vaccine induces stronger $T_{E M}$ effector and $T_{C M}$ central memory cells which correlate with better "short-term protection" against aerosol-induced tuberculosis

Post-vaccination experiments performed on day 21 (Fig. 7a) confirmed that $\mathrm{BCG}^{85 \mathrm{C} 5}$ and $\mathrm{BCG}^{85 \mathrm{CFP}}$ were markedly immunogenic in mice expanding the Ag85B-specific CD4 T cells (Supplementary Fig. S12). Figure $7 \mathrm{~b}, \mathrm{c}$ demonstrate that $\mathrm{BCG}^{85 \mathrm{C} 5}$ generated better protection in lungs and spleens compared with both wt-BCG and BCG $^{85 C F P}$ after primary challenge. Statistical evaluations confirmed that $\mathrm{BCG}^{85 \mathrm{C} 5}$ is superior to $w t-\mathrm{BCG}$ or $B C G^{85 C F P}$ in reducing Mtb counts of lungs (footnote, Fig. 7b, c). On day 60, three additional mice per group were individually analyzed for T cells using flow cytometry; a typical analysis is shown in Fig. $7 d$.

Role of CD4 $T_{E M}$ vs. $T_{C M}$. Since CD4-deficient mice are extremely susceptible to tuberculosis, it is likely that they perform a protective function, although contribution by other immune cells cannot be ruled out. ${ }^{68,69}$ Consistent with this observation, all three $B C G$ vaccines induced robust CD62 $\mathrm{L}^{-} \mathrm{T}_{\mathrm{EM}} \mathrm{CD} 4 \mathrm{~T}$-cell responses in the lungs, spleens, and lymph nodes (Fig. 7e, f, g). Interestingly, $\mathrm{BCG}^{85 C 5}$ and $\mathrm{BCG}^{85 C F P}$ induced better expansion of $\mathrm{CD}^{8} 2 \mathrm{~L}^{+} \mathrm{T}_{\mathrm{CM}}$ CD4 $T$ cells in the lungs ( $p$ groups, a, b, c, d, e; Fig. 7e). However, $\mathrm{BCG}^{85 C 5}$ was better than $\mathrm{BCG}^{85 C F P}$ and $w t-B C G$ in generating more $\mathrm{CD} \mathrm{L}^{-} \mathrm{T}_{\mathrm{EM}}$ CD4 T cells in the lymph nodes ( $\mathrm{p}$ group a, b; Fig. $7 \mathrm{~g}$ ). Since adaptive immune responses in mice depend on mycobacterial antigen production in lymph nodes, these data support the concept that $\mathrm{BCG}^{85 C 5}$ is more immunogenic than either $\mathrm{BCG}^{85 C F P}$ or wt-BCG. ${ }^{59}$

Role of CD8 $T_{E M}$ vs. $T_{C M}$. wt-BCG is a poor inducer of CD8 T cells in mice and cloning of a pore-forming toxin listeriolysin (LLO) enhances the ability of BCG ${ }^{\mathrm{LLO}}$ to induce CD8 T cells. ${ }^{70}$ On the other hand, Mtb infection of mice induces CD8 T cells and prior BCG vaccination can increase their numbers. ${ }^{71}$ Consistent with these observations, all four groups of challenged and vaccinated mice had elevated levels of CD8 $T_{E M}$ in the lungs (Fig. 7e). However, the effects of prior vaccination were striking. Thus, both $\mathrm{BCG}^{85 C 5}$ and $\mathrm{BCG}^{85 C F P}$ increased the $\mathrm{CD}^{8} 2 \mathrm{~L}^{+}$subsets of $\mathrm{CD} 8 \mathrm{~T}_{\mathrm{CM}}$ cells in the lungs compared with mice given wt-BCG and naive mice which experienced only Mtb infection ( $p$ groups, $c, d, e, g$; Fig. 7e). BCG vaccinated mice show a dominance of effector T cells in the lungs. ${ }^{62}$ In this study, all vaccines maintained elevated levels of T-cell effectors in the lungs, although $\mathrm{BCG}^{85 \mathrm{C} 5}$ increased $\mathrm{CD} 62 \mathrm{~L}^{-}$
CD8 $T_{E M}$ in the lymph nodes and was superior to BCG $^{85 C F P}$ and BCG ( $p$ group b, Fig. 7f). Mice chronically infected with Mtb show a dominance of effector over central memory $T$ cells with a reverse profile in the lymphoid organs. ${ }^{57}$ This study shows that, unlike wt$B C G$ vaccinated or Mtb infected mice, recombinant $\mathrm{BCG}^{85 C 5}$ and $B C G^{85 C F P}$ induce a robust $\mathrm{mix}$ of $\mathrm{T}_{E M}$ and $T_{C M}$ in the lungs correlating with better protection against bacterial growth. We propose that $\mathrm{BCG}^{85 \mathrm{C} 5}$ is better than $\mathrm{BCG}^{85 C \mathrm{FP}}$ in generating protection (footnote, Fig. 7b, c; log differences in killing Mtb is also shown) because it induces more functional effectors in the lungs and lymph nodes (Fig. 7e-g).

$\mathrm{BCG}^{85 C 5}$ vaccine induces better multifunctional $\mathrm{T}$ cells and functional CD8 T cells in mice

Cytokine secreting $T$ cells are mediators of $T_{H} 1$ immunity and MFCs mediate better immunity against tuberculosis among mice given systemic, but not subcutaneous vaccination. ${ }^{72}$ BCG $^{85 C 5}$ vaccine induced marginally elevated levels of multifunctional cytokine-secreting cells (MFCs) in the lungs of mice compared with wt-BCG or BCG ${ }^{85 C F P}$ vaccine (Fig. 7h). Likewise, it also enhanced the numbers of TB10.4 $4^{+}$CD8 T cells in the lungs (Fig. 7i). Since antigen-specific cytotoxic T cells lyse infected MФs and their perforin can kill Mtb, their numbers may not necessarily reflect their function. ${ }^{73}$ Thus magnetic bead-purified CD8 T cells of lungs were evaluated for their ability to kill Mtb in MФs using an in vitro cytotoxic-bactericidal assay. Figure $7 \mathrm{i}(\mathrm{CTL})$ indicates that lungderived $C D 8 \mathrm{~T}$ cells of mice given $\mathrm{BCG}^{85 C 5}$ vaccine were more effective in killing Mtb than similar cells obtained from mice given wt-BCG or BCG $^{85 C F P}$ vaccine. Thus, vaccination with $\mathrm{BCG}^{85 \mathrm{C} 5}$ vaccine induced qualitatively and quantitatively stronger $T$ cells in the lungs of mice.

$B C G^{85 C 5}$ vaccine induces stronger $T_{E M}$ and $T_{C M}$ responses after aerosol "rechallenge" with Mtb

BCG vaccination does not protect adults against tuberculosis in developing countries, and even booster vaccination of BCG vaccinated children with MVA-expressing Ag85A failed to generate adequate protection against tuberculosis. ${ }^{74}$ In many viral infection models and Listeria infection, $\mathrm{T}_{\mathrm{CM}}$ mediate longterm immunity. ${ }^{65-67}$ Since $B C G^{85 C 5}$ vaccine induced a robust mix of $T_{E M}$ and $T_{C M}$ (Fig. 7e-g), we hypothesized that $T_{C M}$ could persist longer and mount a stronger recall response, which could be ascertained through a mouse model that allowed the classic expansion, contraction, and recall of memory responses. ${ }^{75}$ In a recently described reinfection model of mouse tuberculosis, CD4 effector and central memory $\mathrm{T}$ cells generated by Mtb infection were soon lost after chemotherapy and bacteria returned. ${ }^{76}$ In a comparable study, TB10.4-specific CD8 T cells underwent a recall expansion after Mtb reinfection of mice, but the efficacy of protection against lung tuberculosis was not determined. ${ }^{57}$ Since these models evaluated "infection-induced" immunity against "reinfection", we developed an improved model in which, the efficacy of "vaccination-induced" memory immunity was tested against infection followed by reinfection (Fig. 7a; rechallenge model). The hypothesis was that improved $\mathrm{BCG}^{85} \mathrm{C5}$ vaccine, unlike Mtb infection, would induce T-cell populations that protect against reinfection.

Figure $8 a$, b illustrates that, among vaccinated mice challenged with Mtb and cleared of organisms, rechallenge of Mtb infection was once again more effectively contained by the $\mathrm{BCG}^{85 \mathrm{C} 5}$ vaccine, which was more effective than either $\mathrm{BCG}^{85 \mathrm{CFP}}$ or wtBCG in the lungs (footnote, Fig. 8a, b). To determine the memory phenotype mediating this protection, $T$ cells harvested from lungs and spleens were analyzed using flow cytometry.

$B C G^{85 C 5}$ induces recall expansion of both CD4 and CD8 effectors and central memory $T$ cells after reinfection. Figure $8 c$ ( $p$ groups $a$, $b, c)$ illustrates that vaccinated and unvaccinated mice showed a 
a

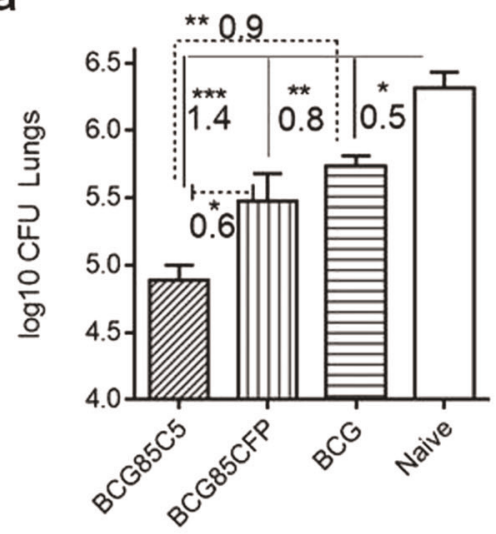

$P$ values

$B C G$ vs naive

BCG85CFP vs, naive

BCG85C5 vs. naive

BCG85C5 vs. BCG85CFP $\mathrm{BCG} 85 \mathrm{C} 5$ vs. BCG
Lungs-

rechallenge

0.01

0.009

0.0061

0.009

0.012 b

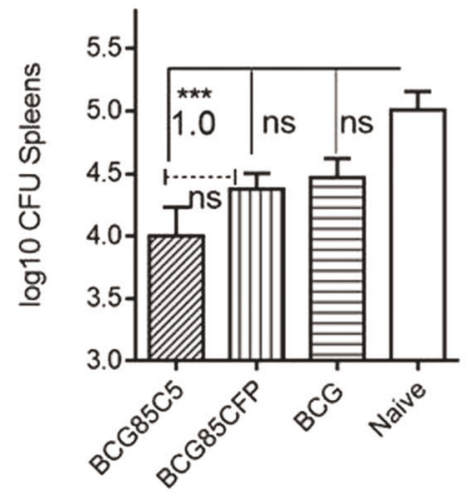

Spleenrechallenge

$B C G$ vs naive BCG 85 CFP vs. naive BCG $85 C 5$ vs. naive

BCG $85 C 5$ vs. BCG85CFP BCG $85 C 5$ vs. BCG
C
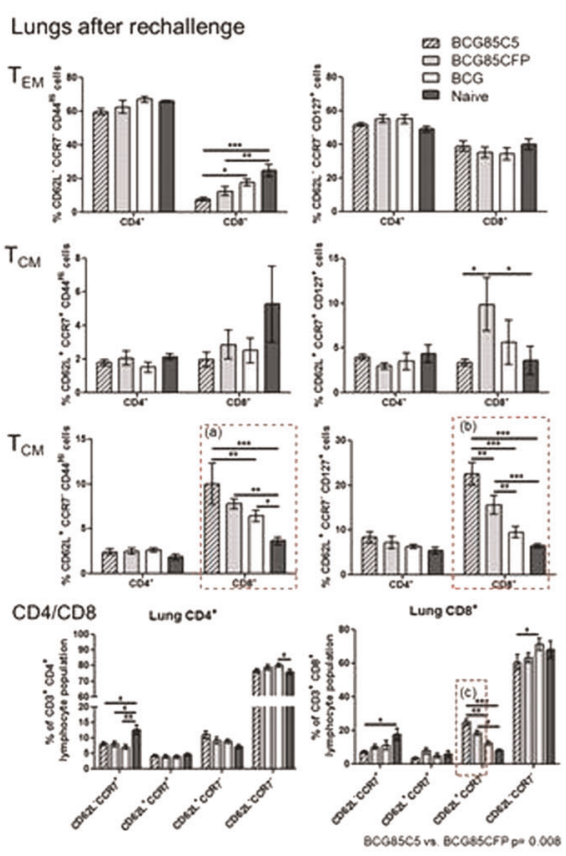

d

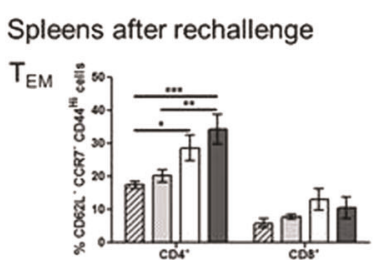

$\mathrm{T}_{\mathrm{CM}}$

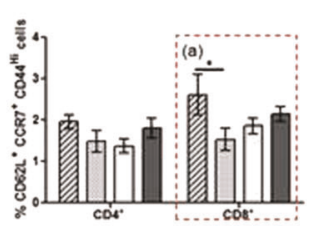

CD4/CD8 spleen CD4.

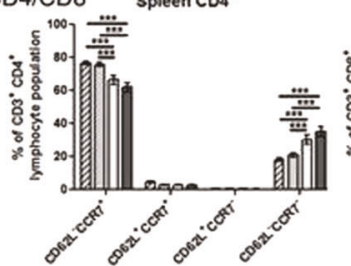

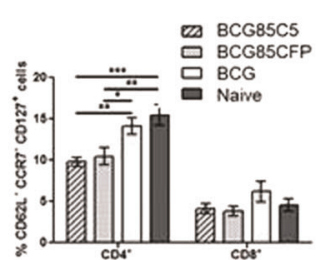

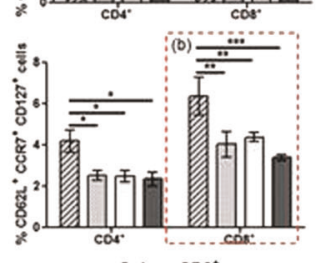

spleen $\mathrm{COB}^{\circ}$

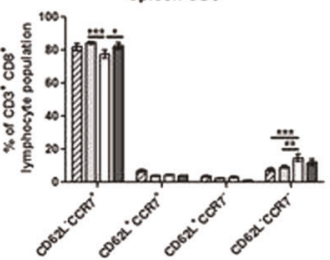

e
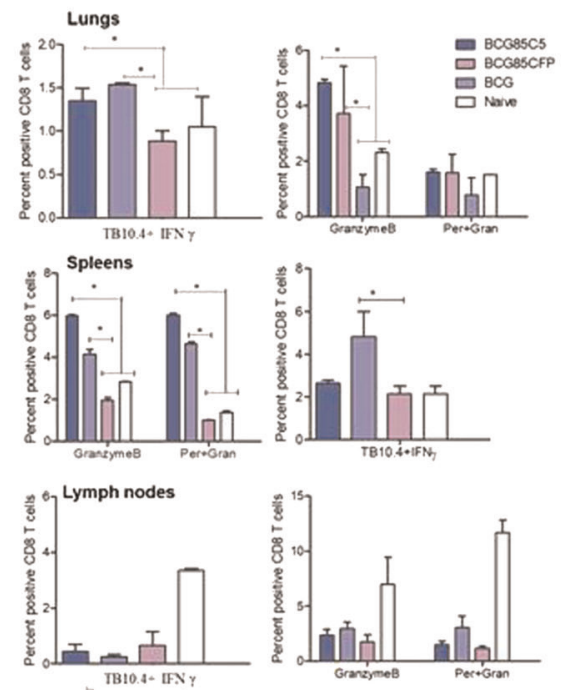

f
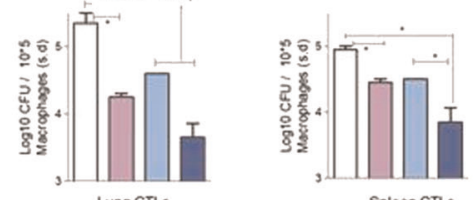

Fig. $8 \mathrm{BCG}^{85 \mathrm{C} 5}$ vaccine induces a robust protection against rechallenge of tuberculosis in mice through expansion of effector ( $\left.T_{E M}\right)$ and central memory $\left(T_{C M}\right)$ T cells. $\mathbf{a}, \mathbf{b}$ CFU counts of Mtb in the lungs and spleens after rechallenge (day 120 ). $B C G^{85 C 5}$ reduces Mtb CFUs in the lung and spleens of mice after rechallenge better than wt-BCG. $P$-values and log 10 difference of CFUs indicated (footnote; $n=5$ mice per group; two-way ANOVA). $\mathbf{c}, \mathbf{d} \mathrm{BCG}^{85 C 5}$ induces both $\mathrm{T}_{\mathrm{EM}}$ and $\mathrm{T}_{\mathrm{CM}} \mathrm{T}$ cells in the lungs and spleens after rechallenge $\left({ }^{*} p<0.01 ;{ }^{* *} p<0.009 ;{ }^{* * *} p<\right.$ 0.007; one-way ANOVA). BCG ${ }^{85 C 5}$ induces more CD62L ${ }^{+}$CD8 central memory T cells in the lungs and spleens compared with $\mathrm{BCG}^{85} \mathrm{CFP}^{\prime}$ and wtBCG (Fig. 7c, p boxes a-c; Fig. 7c, p boxes a, b). wt-BCG induced more CD62L- CD4 effectors in the spleen (Fig. 7d). e CD8 T cells of organs were typed for TB10.4 tetramer-specific CD8 T cells and those expressing granzyme-B and perforin (three individual mice analyzed, and percent positive T cells averaged; * $p<0.0091$; one-way ANOVA). BCG ${ }^{85 C 5}$ increases numbers of TB10.4 ${ }^{+}$CD8 T cells in the lungs and spleens correlating with an increase in expression of granzyme-B and perforin. $f$ CD8 T cell pools purified from lungs and spleens were overlaid on Mtb infected macrophages for bactericidal activity as in Fig. 7i. BCG ${ }^{85 C 5}$ induced CD8 T cells show enhanced killing of intracellular Mtb $\left(^{*} p<0.008\right.$; one-way ANOVA). $P$-values determined using one- or two-way ANOVA with Dunnett's post-test 
rapid expansion of $C D 4-T_{E M}$ and $C D 8-T_{E M}$ after rechallenge. However, $B C G^{85 C 5}$ vaccinated mice had higher numbers of $\mathrm{CD}^{+} 2^{+} \mathrm{CD} 8-\mathrm{T}_{\mathrm{CM}}$ in the lungs, compared with mice given $\mathrm{BCG}^{85 \mathrm{CFP}}$, $w t-B C G$ or naive mice ( $p$ groups $a, b, c ;$ Fig. $8 c$ ). Furthermore, unlike the spleens after primary challenge (Fig. 2f), spleens of $\mathrm{BCG}^{85 \mathrm{C} 5}$ vaccinated but rechallenged mice showed an increase in $\mathrm{CD} 2 \mathrm{~L}^{+} \mathrm{CD} 8-\mathrm{T}_{\mathrm{CM}}$ response ( $\mathrm{p}$ groups $a$, $b$; Fig. $8 d$ ). Thus, protection induced by $\mathrm{BCG}^{85 \mathrm{C} 5}$ against secondary aerosol challenge correlated with an expansion of both CD4 and CD8 effectors and an enhanced central memory T-cell response in the lungs and spleens. To further define the basis of long-term memory, $T$ cells of mice rested after chemotherapy but before rechallenge were analyzed for intracellular expression of "T-box expressed in T cells" (T-bet) and Eomesodermin (Eomes), markers respectively of $T_{E M}$ and $T_{C M}$. The data show that $B C G^{85 C 5}$ induced more Eomes ${ }^{+} \mathrm{T}$ cells than either BCG ${ }^{85 \text { CFP }}$ or wt-BCG (Supplementary Fig. S13). This is consistent with the report that Eomes facilitates the emergence of long living $\mathrm{T}_{\mathrm{CM}}{ }^{77}$

$\mathrm{BCG}^{85 \mathrm{C5}}$ vaccine-induced $\mathrm{CD} 8 \mathrm{~T}$ cells are functional after secondary challenge with Mtb. That CD4 T cells protect against tuberculosis by secreting $T_{H} 1$ cytokines is well established. Since the recall $\mathrm{T}$-cell response to Mtb reinfection among vaccinated mice was associated with a stronger CD8 T-cell component (Fig. $8 c, d$ ), these cells were further analyzed using the TB10.4 tetramer and intracellular stains for granzyme-B and perforin followed by an in vitro cytotoxic-bactericidal assay. ${ }^{57}$ Figure $8 \mathrm{e}$ illustrates that the lungs and spleens of $\mathrm{BCG}^{85 \mathrm{C} 5}$ and $\mathrm{BCG}^{85 \mathrm{CFP}}$ vaccinated mice

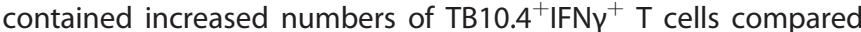
with wt-BCG vaccinated or naive mice. Furthermore, $\mathrm{BCG}^{85 \mathrm{C} 5}$ vaccinated mice contained more granzyme- $B$ and perforin expressing CD8 T cells. Coincident with this observation, magnetic bead-purified CD8 $T$ cells from lungs and spleens of BCG ${ }^{85 C 5}$ vaccinated mice had increased cytolytic and bactericidal activity in vitro and killed intracellular Mtb (Fig. 8f).

\section{DISCUSSION}

BCG is the most frequently used live attenuated (LAV) bacterial vaccine in humans, although it provides poor protection for adults against tuberculosis. $B C G$ is unique inducing adult type $T_{H} 1$ immunity among neonates even when given at birth. In addition, BCG not only protects children against extra-pulmonary tuberculosis but also induces "trained" immunity, which protects children against multiple other infections. ${ }^{78-80}$ Thus there is a strong rationale to improve $B C G$ vaccine for neonates, and some even recommend revaccination with $\mathrm{BCG}^{81,82}$ In additional support, studies show that neonatal responses to BCG vaccine are suboptimal. Neonates responded to antigens with more IL-10 which could be reversed via TLR stimulation restoring a robust proinflammatory profile and $T_{H} 1$ response to vaccines. ${ }^{83-86}$ Furthermore, infants produced weaker pro-inflammatory responses involving IL-12, TNF- $\alpha$, and IL- $\beta$ thereby enhancing susceptibility to tuberculosis. ${ }^{87}$ Polymorphisms in the TLR-1/2/6 pathway were also proposed to affect the efficacy of BCG since infants of tuberculosis endemic countries routinely received this vaccine. $^{88,89}$

Despite being an LAV, BCG vaccine does not seem to induce long-lasting immunity, and indeed, it is perplexing that young adults who are otherwise immune competent are susceptible to tuberculosis in endemic areas. In our earlier studies, we sought to determine the molecular basis for the reduced immunogenicity of wt-BCG. ${ }^{13,14,90,91}$ LAVs are internalized into phagosomes which fuse with lysosome to generate peptides for the MHC-IIdependent activation of CD4 T cells. Since BCG evades PL fusion, we induced autophagy through either rapamycin pre-activation of DCs or mice or through hyperexpression of Ag85B that triggered autophagy in APCs, enhancing the efficacy of BCG $^{85}$ vaccine. ${ }^{14,20}$ Three seminal studies including ours document that autophagy enhances MHC-II- and MHC-I-dependent antigen presentation enhancing respectively, CD4 and CD8 T-cell activation. ${ }^{14,15,92}$ Here, we expressed the Mtb-derived C5 autophagy-inducing peptide which also stimulated TLR-2 to culminate in the first autophagyinducing recombinant BCG vaccine.

The discovery of autophagy-inducing and TLR-2 activating C5 peptide was fortuitous and highlighted the enigmatic observation that the immunodominant complex of ESAT- 6 and CFP-10 contain both immune-suppressing and activating peptide motifs. While CFP-10-derived peptides were stimulatory, ESAT- 6 contained both stimulatory and inhibitory motifs. Both Mtb and BCG secrete antigens, and it has been suggested that they bind and modulate APCs through their receptors. Indeed, ESAT- 6 suppresses MФs to IFN- $\gamma^{25-27}$ and induces suppressive IL- 6 and TGF- $\beta$ through TLR-2 signaling, thereby affecting cytosolic translocation of Mtb. ${ }^{93,94}$ Therefore during tuberculosis pathogenesis, ESAT-6 and CFP-10 complex perhaps skews immune responses beneficial to the pathogen. ${ }^{27}$ On the other hand, CFP-10 elicits robust response among humans and contained the autophagy-inducing and TLR-2 activating $\mathrm{C} 5$ motif. ${ }^{95}$ By expressing the $\mathrm{C} 5$ immunogenic moiety of $\mathrm{Mtb}$ in $\mathrm{BCG}^{85 \mathrm{~B}}$, we markedly improved $\mathrm{BCG}$ vaccine as outlined below.

The immunogenicity of BCG vaccine, and its ability to activate CD4 $T$ cells, depends upon three critical events; efficient processing of peptides in lysosomes, peptide epitope complexation with MHC-II, and their export to plasma membranes, where CD4 $T$ cells can be activated in a milieu rich in pro-inflammatory $\mathrm{T}_{\mathrm{H}} 1$ cytokines. Interestingly, wt-BCG vaccine shows deficiencies related to these aspects.

Thus, BCG evades PL fusion ${ }^{5,96}$ and autophagy ${ }^{97}$, and we demonstrated that rapamycin-induced autophagy delivered BCG to lysosomes increasing antigen presentation in APCs and vaccine efficacy in mice. ${ }^{14}$ In this study, expression of C5 peptide in $\mathrm{BCG}^{85 \mathrm{C} 5}$ brought out a novel effect of $\mathrm{C} 5$ peptide; it increased the TLR-2-dependent LC3 labeling of vaccine and its autophagydependent delivery to lysosomes (Fig. 5). Increased lysosomal delivery of $\mathrm{BCG}^{85 \mathrm{C} 5}$ vaccine enhanced antigen presentation, consistent with the observation that TLR-2-mediated autophagy increases MHC-II-dependent antigen presentation. ${ }^{98}$ It is important to note here that $\mathrm{BCG}^{85 \mathrm{C5}}$ vaccine enhanced antigen presentation and $T_{H} 1$ cytokines in both $M \Phi s$ and $D C s$. We showed earlier that rapamycin-activated DCs containing BCG were better than BCG alone in protecting mice against tuberculosis, thus highlighting the importance of DCs during vaccination. ${ }^{99}$ These observations are consistent with the observation that autophagy to increases both MHC-II- and MHC-I-dependent antigen presentation. ${ }^{14,15,92}$ Therefore, we propose the novel paradigm that $\mathrm{C} 5$ enabled $\mathrm{BCG}^{85 \mathrm{C} 5}$ vaccine to overcome phagosome maturation block.

APCs present the lysosome-generated peptide epitopes through MHC-II to CD4 T cells expanding a critical arm of $T_{H} 1$ immunity. Paradoxically, both Mtb and BCG vaccine suppress the MHC-II expression in mouse and human APCs, and also desensitize the MФ responses to IFN- $\gamma^{43,48,100-102}$ While a 19-kDa lipoprotein of BCG vaccine decreases MHC-II expression, our data show that C5 peptide overcomes the inhibitory effect and enhances MHC-II expression by reducing its ubiquitination and degradation (Fig. 4). This is consistent with our previous observation that commercial ligands for TLR-1/2 downregulate the MARCH1-ubiquitinating enzyme, thereby increasing the surface expression of MHC-II in APCs. ${ }^{46}$ Importantly, unlike previous studies, expression of $\mathrm{C} 5$ peptide in $\mathrm{BCG}^{85 \mathrm{C5}}$ vaccine bypassed the suppressive effects of BCG ligands like the $19-\mathrm{kDa}$ lipoprotein and LAM. ${ }^{43,103}$ A second novel attribute of $\mathrm{BCG}^{85 \mathrm{C5}}$ vaccine is therefore a better $\mathrm{MHC}-\mathrm{II}$ expression and antigen presentation.

$w t-B C G$ induces a variety of cytokines in human monocyte-T cell co-cultures, but it is a poor inducer of IL-1 $1 \beta$ when given to humans. ${ }^{104,105}$ In addition, among neonates, it induces a poor pro- 
inflammatory cytokine response that could enhance susceptibility to tuberculosis. BCG ${ }^{85 C 5}$ vaccine induced TLR-2 activation and enhanced the secretion of IL-12, TNFa, and IL-1 $\beta$ (Figs 2, 3). Presumably, the induction of autophagy by $\mathrm{BCG}^{85 C 5}$ vaccine led to a better IL-1 $\beta$ response, since secretion of vesicles containing IL-1 $\beta$ is partly dependent on autophagy and furthermore, IL-12, TNF- $a$, and IL-1 $\beta$ self-regulate autophagy through a loop mechanism. ${ }^{106}$ Neonates have been reported to produce more IL-10 in response to antigens ${ }^{83-86}$ and show a weaker pro-inflammatory IL-12, TNF$a$, and IL- $\beta$ response enhancing susceptibility to tuberculosis. ${ }^{87}$ Thus, the third attribute of $B C G^{85 C 5}$ vaccine is its ability to induce a robust IL-12, TNFa, and IL-1 $\beta$ response compared with wt-BCG (Figs 2,3 ). It is relevant to note here that IL-12 induces T-bet enhancing effector function in $T$ cells $s^{107,108}$; TNF-a mediates epigenetic modulation of T-helper lineage ${ }^{109}$, and IL- $\beta$ regulates Tcell proliferation and helps to bypass tolerance. ${ }^{110}$

These mechanistic in vitro studies suggested that the $\mathrm{BCG}^{85 C 5}$ vaccine can elicit equally stronger and longer lasting T-cell response in mice. Figure 7 , for example, shows that $\mathrm{BCG}^{85 C 5}$ induced strong antigen-specific CD4 (Ag85B-specific) and CD8 (TB10.4-specific) T cells among mice correlating with a better TLR2-dependent protection against tuberculosis when compared with both wt-BCG and $\mathrm{BCG}^{85}$. Both these antigens are also strongly recognized by humans. ${ }^{74,111}$

An interesting aspect of BCG vaccination in mice is that it protects mice against primary challenge by about $1-\log _{10}$ failing to eliminate Mtb, and furthermore poorly protects against reinfection. We addressed this defect by hypothesizing that robust immunity requires both a strong effector $T$-cell $\left(T_{E M}\right)$ response that generates short-term protection, and a critical central T-cell memory $\left(T_{C M}\right)$ response necessary for a long-term protection. It is relevant to recall here that many virus vaccines induce robust effector and central memory T-cell responses. Based on this logic, it was anticipated that modified vaccinia Ankara (MVA)-based vaccines expressing multiple Mtb-derived antigens should induce robust effector and central memory $T$ cells. Although MVA-Ag85A followed by adjuvant-Ag85A booster did induce effector and central memory T cells in mice, to the best of our knowledge, a correlation between $T_{E M}$ and $T_{C M}$ to protection against tuberculosis has not been demonstrated. ${ }^{112}$ In this connection, it is important to note that wt-BCG induces a robust $T_{E M}$ response, but a weaker $T_{C M}$ response in mice. ${ }^{113}$

It is intriguing to observe that many viral vaccines can induce long-lasting immunity in humans although, few if any bacterial vaccines seem to induce long-lasting protection in humans. Using virus and Listeria infection models, Obar and Lefranquois proposed that both $\mathrm{T}_{E M}$ and $\mathrm{T}_{\mathrm{CM}}$ cells are induced during the initial infection, although the $\mathrm{T}_{\mathrm{CM}}$ cells are less prominent during initial stages, and become dominant over time with significant changes associated with the upregulation of the memory marker CD62L. ${ }^{65-67,114}$ They also proposed that the "strength" of the initial interaction between APCs and T cells determines the $T_{C M}$ response whereas, cytokines like IL-12, IL-7, and type I-IFNs affect the T-bet and Eomes transcription factors, which in turn regulate the expansion and maintenance of $T_{E M}$ and $T_{C M}$ lineages, respectively. ${ }^{115,116}$ Importantly, vaccine-induced APC-T cell interactions need to occur in an optimal environment with durability of antigen for long-term memory to emerge. ${ }^{65-67,114,117,118}$ Notably, "duration of contact with antigen" was thought to be critical for memory development. ${ }^{118}$ Since $\mathrm{BCG}^{85 C 5}$ induced strong antigen presentation both in vitro (Figs 1-4) and in vivo (Fig. 7), we proposed that it would enable long-term memory in mice against tuberculosis. We noted that the yellow fever virus vaccine that induces long-term immunity activates multiple TLRs. ${ }^{19}$

An improved mouse model of vaccination illustrated that $B C G^{85 C 5}$ expanded both $T_{E M}$ and $T_{C M}$ which correlated with a stronger protection against primary challenge as well as rechallenge with tuberculosis (Figs 7,8 ). Importantly, the vaccine induced robust CD4 T cells against Ag85B, a major component of subunit vaccines against tuberculosis in humans and mice. In fact, a single dose of Ag85B vaccine elicited a CD4 T-cell response lasting a year in human volunteers. ${ }^{120}$ In addition a strong response of TB10.4-specific CD8 T cells were induced, and TB10.4specific CD8 $T$ cells were induced; this antigen is recognized among humans. ${ }^{111}$ Importantly, BCG $^{85 C 5}$-induced CD8 T cells were functional against Mtb within MФs.

It is known that T-bet induces $\mathrm{T}_{\mathrm{EM}}$, while Eomes regulates $\mathrm{T}_{\mathrm{CM}} \cdot{ }^{115,116} \mathrm{BCG}^{85 C 5}$ induced an expansion of $\mathrm{T}_{\mathrm{EM}}$, contraction of this population during drug therapy, and allowed re-emergence after rechallenge; these were associated with a stronger expression, respectively, of T-bet and Eomes by the $\mathrm{BCG}^{85 C 5}$ vaccine (Fig. 8) (Supplementary Fig. S10). Thus, it was superior than wt-BCG by facilitating the transition of effector T-cell populations to longerlasting central memory $\mathrm{T}$ cells as evident from the improved model of vaccination (Fig. 8a). To the best of our knowledge, $B C G^{85 C 5}$ is unique in generating protection both against primary and rechallenge of tuberculosis in the mouse model.

The continued occurrence of active tuberculosis in BCG vaccinated population and the failure of certain subunit vaccines to boost BCG-induced immunity has led to varied attempts to improve tuberculosis vaccines. However, BCG is the only live attenuated safe vaccine that elicits adult-type Th1 immunity in neonates, and even generates substantial "trained" immunity that protects children against other infections. ${ }^{121}$ BCG continues to be a an essential vaccine in developing countries and many even recommend revaccination. ${ }^{81,82}$ This study generates optimism that it is feasible to design a recombinant BCG vaccine that enhances autophagy-dependent interactions between neonatal and adult APCs and T cells to generate long-lasting protection.

\section{MATERIALS AND METHODS}

MФs and DCs

Primary bone marrow-derived MФs (MФs) and DCs from C57BI/6 mice or TLR-2 KO mice (4-8 weeks old M/F, Harlan or Jackson, USA) were grown in Iscove's medium with $10 \%$ FBS (IDM) and $10 \mathrm{ng} / \mathrm{mL}$ GM-CSF and CD11c beads (Miltenyi Inc, USA; 130-052-001) were used to deplete DCs from bone marrow cells cultured for 7 days. The CD11b + CD11c-MФs or CD11c bead-purified CD11C + DCs were plated in GM-CSF-free medium and incubated overnight at $37^{\circ} \mathrm{C}$. They were then infected with Mycobacterium bovis BCG (Pasteur strain, ATCC $35734 ; \mathrm{MOI}=1$ ), prepared as a single-cell suspension, for $4 \mathrm{~h}$ on a shaker at $37^{\circ} \mathrm{C}$ washed and supernatants or cell lysates collected for further analysis. Viability of MФ and DCs was $>90 \%$ using trypan blue at the time of plating or at the end of experiments.

Recombinant CFP-10 and ESAT-6 proteins and synthetic peptides These were a kind gift from $\mathrm{BEI}, \mathrm{NIH}$. The overlapping peptides of both CFP- 10 and ESAT- 6 were synthesized to $>90 \%$ purity by Genscript (USA). Thus, LPS-mediated TLR-4 activation was not an issue for the peptides.

\section{Construction, expression, and purification of ESAT-6 truncated proteins}

ESAT- 6 WT and the truncated proteins were obtained as previously described. $^{122,123}$ Briefly, the full-length ESAT-6 gene (wt, residues 1-95) immediately followed by a C-terminal His6 tag was cloned into pET22b at the Ndel/Xhol sites. The DNA encoding C-terminal truncated ESAT-6 (residues 1-85, $\triangle C$ ), which is immediately followed by a His6 tag, was obtained by PCR and cloned into pET22b at Ndel/Xhol sites. The DNA encoding the N-terminal truncated ESAT-6 (residues $11-95, \Delta N$ ) and the DNA encoding both $\mathrm{N}$ - and C-terminal truncated ESAT-6 (residues 11-85, $\Delta N+C$ ), both of which were followed by a C-terminal His6 tag, were obtained by PCR and cloned into PGEX4T-1 vector at BamHI/Xhol sites.

ESAT- 6 wt and truncated proteins were expressed and purified as previously described. ${ }^{122,123}$ Briefly, pET22b-ESAT-6(WT) and pET22b-ESAT-6 $(\triangle C)$ were expressed in BL21 (DE3) cells. The inclusion body was isolated and then solubilized in $8 \mathrm{M}$ urea. The proteins were refolded on a nickel column and eluted with an imidazole gradient. The eluted proteins were 
further clarified by size exclusion chromatography to $90 \%$ purity. GST- $\Delta N$ and GST- $\Delta N+C$ were expressed as soluble proteins in BL21 (DE3) cells. The fusion proteins were purified on a glutathione-Sepharose $4 B$ column. The purified GST fusion proteins were cleaved with thrombin, and Histagged $\Delta N$ and $\Delta N+C$ were purified on a nickel column, followed by size exclusion chromatography.

In vitro presentation Ag85B to BB7 CD4 T cells

MФs and DCs were cultured in IDM and used as monolayers in 24-well plates for IL-2 assays. The Ag85B epitope (240-254; FQDAYNAAGGHNAVF)specific T-cell hybridoma (BB7) was a kind gift of Drs. Cliff Harding and Henry Boom, CWRU, USA. Untreated or peptide activated APCs were infected with various $B C G$ vaccine strains $(\mathrm{MOI}=1)$ (washed and sonicated to obtain single cell CFU suspension) for 2 or $4 \mathrm{~h}$ followed by washing of monolayers with medium and over lay with $T$ cells (20:1 ratio). Supernatants were collected 4 or $24 \mathrm{~h}$ later as indicated and tested for IL-2 using sandwich ELISA.

\section{Mycobacteria}

Wild-type BCG (wt-BCG Pasteur) (ATCC \#35734), Mtb Erdman (\#35801) were from the American Type Culture Collection (ATCC), and were grown in Dubos' broth and used afresh after three washes in PBS. Cultured mycobacteria were routinely $>90 \%$ viable as evaluated by fluorescein diacetate stains (Invitrogen, USA). Recombinant BCG including gfp-or rfpBCG were grown in kanamycin containing $7 \mathrm{H} 9$ broth. Single-cell suspensions for APC infection, aerosol infection, or vaccination of mice have been described earlier. ${ }^{14}$

\section{Western blot experiments}

Six well plates were seeded with primary MФs. They were activated with peptides as indicated for $4 \mathrm{~h}$ followed by addition of wt-BCG (MOI of 1). At time points, MФs were washed thrice with $\times 1$ PBS, and $200 \mu \mathrm{l} 0.05 \%$ SDS/ APM (anti-protease) mix was added to each well and incubated for $15 \mathrm{~min}$. Lysates were then collected, and protein quantification (BCA, Pierce 23225) was performed. For western blot, $25 \mu \mathrm{g}$ of the total protein was loaded per well of Bio-Rad criterion gels and transferred to PVDF membranes. Antibodies against both the native and phosphorylated proteins of c-Jun and CREB were used at a dilution of 1:500 (c-Jun (60A8), Cell Signaling \#9165; (1-C-Jun (Thr91), Cell Signaling \#2303; CREB (48H2), Cell Signaling \#9197; ( 1 -CREB (Ser133), Cell Signaling \#9191). Secondary antibody was added (1:1000 a-rabbit, Cell Signaling \#7074 s), and the membranes were then developed using ECL kit. Other inhibitors used were from EMD chemicals: 559388-SB 202190 p38 map kinase inhibitor II; 328006-ERK Inhibitor; 420119-JNK Inhibitor II; 217505, CBP-CREB Interaction Inhibitor. Western blot and densitometry analysis data are shown as mean band density normalized relative to $\beta$-actin or phosphorylated proteins $(n=3)$.

\section{Inhibition of TLR signaling in MФs and DCs}

Various inhibitors of mitogen-activated kinases (MAPK), AP-1/CREB were used to block signaling due to TLRs. TRAF-6 inhibitor peptide set and NF-kB inhibitor peptide set (\#2004) were from Imgenex, USA, and IRAK1/4 inhibitor (\#15409) was from Sigma (USA). AP-1 inhibitor (\#SR11302) was from Tocris (USA). MФs were treated with inhibitors for $2 \mathrm{~h}$, activated with TLR-ligands for $2 \mathrm{~h}$, and infected with BCG for $2 \mathrm{~h}$ prior to fixation and assay of surface MHC-II or antigen presentation. This rapid procedure was adapted to ensure $>90 \%$ viability of MФs.

\section{MHC-II assays}

Surface staining for MHC-II and western blots for ubiquitinated MHC-II have been described in detail elsewhere. ${ }^{46}$ Briefly, primary MФs or DCs were incubated with inhibitors of MAPK, AP-1, and CREB for $2 \mathrm{~h}$, added with $\mathrm{C} 5$ peptide for $2 \mathrm{~h}$, mixed with BCG for $2 \mathrm{~h}$, and stained for MHC-II before analyzing using flow cytometry. Short-term activation and infection was used to prevent viability loss in this experiment and to minimize adherence of MФs. Trypan blue staining showed $>95 \%$ viability in $M \Phi$ s and DCs after treatments.

\section{Autophagy experiments}

$M \Phi s$ and DCs were infected with either $r f p$ - or $g f p B C G(M O I=1)$, with or without added peptides and after infection of $4 \mathrm{~h}$ with mixing, washed, and fixed for immunostains with antibodies against LC3, LAMP1, and CD68, as described..$^{14}$ MФs were either derived from C57BI/6 or TLR-2 KO mice; RAW.A4 cells expressing gfpLC3 was prepared in the lab of Dr. Eissa, and has been published. ${ }^{99}$ Confocal images were acquired with a Nikon-N90 florescent microscope with NIS-Elements software that merges green and red fluorescence and computes colocalization and yields pixelated data 14 125 . Visual scoring by an unbiased observer on blinded samples were compared with a computer-assisted image analysis using ImageJ software (http://rsbweb.nih.gov/ij/). To define colocalization, at least $50 \%$ or more of individual BCG bacilli were scored yellow. Percent colocalization was determined by counting $\mathrm{gfp} / \mathrm{rfp}-\mathrm{BCG}$ per $M \Phi$ in 50 separate $M \Phi$ s in triplicates and averaging them for an experiment done twice on separate days. The colocalization scores shown in figures are for one of two similar experiments (mean $\pm \mathrm{SD}$ ).

\section{$P$-values for all non-mouse experiments}

The data were analyzed using one-way analysis of variance (ANOVA) with Dunett's post hoc test.

\section{Mouse tuberculosis protection assay}

C57BI/6 mice (4-6 weeks of age, M/F) were vaccinated with one dose of BCG ( $10^{6}$ CFU per dose) given alone or mixed with CFP-10 or ESAT-6derived peptides $(25 \mu \mathrm{g} /$ mouse dose during first dose in Freund's incomplete adjuvant). Mice were given a booster dose of the same peptide without adjuvant 2 weeks later. Mice were aerosol challenged with 100 CFU of Mtb H37Rv using a Glas-Col aerosol chamber (Terre Haute, IN), as described. ${ }^{14}$ Mice were rested for 4 weeks, and killed for lung CFU counts by plating lung homogenates on $7 \mathrm{H} 11$ agar plates. CFU counts were expressed as log10 per organ (four mice per time point per vaccine combination; $p$-values determined using one-way ANOVA).

\section{Construction of recombinant $B C G\left(B C G^{85 C 5}\right)$ that overexpresses fused Ag85B and C5 peptide}

The BCG vaccine overexpressing, secreted Ag85B $\left(\mathrm{BCG}^{85 \mathrm{~B}}\right.$ ) has been described by us earlier. ${ }^{14}$ To prepare the new vaccine construct, a plasmid was first constructed that can express $A g 85 B$ and $C 5$ peptide fusion and for this purpose, two oligonucleotide primers RV1886H and AG85BCFP20AA were synthesized. Primer RV1886H (5'-GCCACGGGATCCAATTCGTTG CGGTCCAAGATGGCGCCGTCT- $3^{\prime}$ ) is based on the DNA sequences upstream to the coding region of the gene Rv1886C that codes for Ag85B of $M$. tuberculosis. A BamHI site was engineered in this primer. The primer AG85BCFP20AA (5'-AGTAGCGAATTCTCACTAGTCGAGTTCCTGCTTCTGCTTA TTGGCTGCTTCTTGGAAGCGCACCACCGCGGCCTGGGCGCCGGCGCCTAACGA ACTCTGCAGGTCACC $-3^{\prime}$ ) is based on the $3^{\prime}$ sequence of $R v 1886 \mathrm{C}$ and sequences for the $20_{\mathrm{aa}}$ region (AQAAVVRFQEAANKQKQELD, representing C5 peptide) of the CFP-10 protein encoded by Rv3874 of M. tuberculosis. This primer was engineered to have a unique EcoRI restriction site. These two primers were used in PCR to amplify a DNA region of approximately $1520 \mathrm{bp}$ which has sequences of the promoter region of Rv1886C and coding sequences for full Ag85B protein and 20 AA peptide region from CFP-10 protein. The plasmid pSDRV18861 was used as a template for this reaction, which has full Rv1886C gene and its promoter region. The PCR amplified fragment was initially cloned into a pCR2.1 vector (Invitrogen). After confirming the sequences of the cloned fragment by DNA sequencing, the fragment was cleaved by cutting with BamHI and EcoRI, and subsequently cloned into pMV206 cut with similar enzymes. The resulting plasmid pSD85BC5 was transformed into wild-type BCG to create $B C G^{85 B C 5}$ using standard protocols. Overexpression of $A g 85 B$ and $C 5$ peptide was confirmed with immunoblot using antibodies against purified Ag85B and CFP-10 proteins of Mtb (both from BEl, NIH) (Supplementary Fig. S14). The ability to secrete Ag85B was measured using an antigen presentation assay described below. The presence of $\mathrm{C} 5$ was confirmed using T cells of C57BI/6 mice immunized with CFP-10 protein given subcutaneously (two doses of $10 \mu \mathrm{g} /$ dose each given 2 weeks apart) with Freund's incomplete adjuvant. The T cells of these mice but not naive mice, elicited IFN- $\gamma$ release when activated with $M \Phi s$ containing $B C G^{85 C 5}$ but not $\mathrm{BCG}^{85 \mathrm{~B}}$ (Supplementary Fig. S10).

\section{Mouse vaccine experiments}

The main mouse vaccine validation protocol is identical to the NIH mouse model and is illustrated in Fig. 7 and in the first half of Fig. 7a (up to 60 days). Two types of mouse vaccine models are shown in Fig. 7. Figure 7a 
tested wild-type C57BI/6 mice and matching TLR-2-KO mice from Jackson Inc. Figure 8 a used only wt-C57BI/ 6 mice. Age- and sex-matched mice (6-8 weeks) were tested naïve or vaccines given s.c. to the hind legs of mice (estimated to contain $1 \times 10^{6}$ CFUs through plating on $7 \mathrm{H} 11$ agar). After vaccination, at time points indicated, mice were aerosol challenged with approximately 100 CFU of virulent Mtb Erdman using a Glas-Col (Indiana, USA) aerosol apparatus. Four weeks after challenge or at indicated times, organs were harvested for CFUs as described before. Significance of differences in the CFU counts was calculated using two-way ANOVA as outlined below. Five mice per vaccine strain were used and three-four individual mice per time point for flow-cytometry analysis. Challenge Mtb was differentiated from BCG vaccine by culturing organ homogenates in $7 \mathrm{H} 11$ agar containing Thiophene-2- carboxylic acid hydrazide $(10 \mu \mathrm{g} / \mathrm{mL})$, which inhibits $B C G$, but not wild-type Mtb.

Post-vaccination follow-up. Mice were killed on day 21 post vaccination (three or four mice per group) and individually analyzed as follows. ${ }^{56}$ Splenocytes were stained using tetramers as described below. T cells from spleens were also stained for multifunctional cytokines after they were restimulated with a soluble protein antigen from Mtb Erdman as described before. ${ }^{124}$ Purified protein antigens used for recall immune responses (ESAT6 , CFP-10, antigen-85B were from BEI (NIH). IFN- $\gamma$ assays were performed by stimulating splenocytes using specific protein antigens added at $1 \mu \mathrm{g} / \mathrm{mL}$ and $18 \mathrm{~h}$ supernatants assayed for IFN- $\gamma$ using sandwich ELISA.

In vitro cytotoxic and bactericidal test of magnetic bead-purified CD8 $T$ cells. The bone marrow-derived macrophages were infected with Mtb (MOI of 1 ) for $4 \mathrm{~h}$ and washed thoroughly to remove external bacteria. CD8 T cells were purified from the lungs or spleens of mice $(N=3)$, pooled and overlaid on Mtb-infected macrophages at a 1:100 ratio. Viability of macrophages using trypan blue was $>90 \%$ after $72 \mathrm{~h}$, at which time point, lysates of macrophages were plated for CFUs.

Drug-induced clearance. Isoniazid (INH) and rifampin were mixed in saline and mice given $10 \mathrm{mg} / \mathrm{kg}$ dose daily by gavage for 3 weeks following which mice were rested as indicated. ${ }^{125}$

P-value for CFU counts, five mice per time point. Mice were left untreated (five per group) or vaccinated with BCG followed 4 weeks later with aerosol challenge with Mtb. Mice were killed, and colony counts of Mtb measured in the lungs. The data are plotted as $\log _{10}$ CFU per organ per mouse. Allowing for a statistical power of $0.8-0.9$, and a usual variance of $0.1-0.2$ $\log _{10} \mathrm{CFU}$, a reduction in the mean CFU values between saline controls and test groups of about $0.6-0.7 \log _{10}$ CFU is significant, when $n=5$ animals are used (two-way ANOVA with Turkey's post-hoc test used for $p$-values).

Flow cytometry of lung T-cell numbers and memory T cells

$T$ cells of the infected lungs post challenge were enumerated as per published procedures. Briefly, 3-4 mice per dose per group were killed, lungs, spleens, and lymph nodes were teased in IDM, T cells enriched and stained for CD4 and CD8 T cells in addition to surface receptors and intracellular IFN- $\gamma$ followed by flow-cytometric analysis. The results were also reported as absolute numbers of T cells per organs after performing an initial organ cell count using trypan blue and staining and acquiring a fixed number of cells. (a) Lungs were processed with $1 \mathrm{mg} / \mathrm{ml}$ collagenase and $1 \mathrm{mg} / \mathrm{ml}$ elastase (Sigma Biologicals, USA) to break down the fibrous tissue material. It was then passed through cell strains and teased using frosted slides till a suspension of cells was obtained. The tissues were further treated with ACK lysis buffer (BioWhittaker, USA) to remove RBCs. Abs (CD4-FITC, CD8-FITC, IFNY-APC, Perforin-APC, Granzyme-B-PE, T-bet-PE, Eomes-APC, PD1-APC, KLRG1-FITC, CD44-FITC, CD127-PE, CD62L-APC, CD3APCCy7) (T-bet-PE, Eomes-APC, Perforin-APC, and Granzyme-B-PE) were purchased from Ebioscience, USA. Tetramers were obtained from NIH core facility, Emory University. Single-cell suspensions from spleens were stained with $1-A(b)$ Mtb antigen-85B precursor (FQDAYNAAGGHNAVF) tetramer-APC/PE or with I-A(b) human class II-associated invariant chain peptide (PVSKMRMARPLLMQA) tetramer-APC as a negative control (NIH MHC Tetramer Core Facility at Emory University, Atlanta, GA), and were identified by flow cytometry. It should be noted that not all tetramers were compatible for $\mathrm{C} 57 \mathrm{BI} / 6$ genetic background mice. For phenotype analysis, we used a minimum number of 50 events in the tetramer gate, with a mean of 180 events. Flow staining was performed as per BD Biosciences protocol. Cell events were collected using Beckman-Coulter-Gallios cytometer, and the cytokine profile was analyzed using FlowJo software
(Tree Star, Ashland, OR). The graphs were plotted and analyzed using graph pad prism software. The other tetramers used in this study were: $\mathrm{H}$ 2D(b) Mtb32A 309-318 GAPINSATAM (PE-Labeled Tetramer) ${ }^{126} ; \mathrm{H}-2 \mathrm{~K}(\mathrm{~b})$ Mtb TB10.4 4-11 IMYNYPAM (PE-Labeled Tetramer) ${ }^{127} ; \quad \mathrm{H}-2 \mathrm{D}(\mathrm{b}) \quad M$. tuberculosis PstS - SGVGNDLVL (APC-Labeled Tetramer). ${ }^{128}$ Of these one tetramer had not been tested earlier and the epitope was based in predictive algorithm (Immune epitope database); $\mathrm{H}-2 \mathrm{D}$ (b) M.tuberculosis ESAT-6 protein (aa17-25)-AIQGNVTSI (PE-Labeled Tetramer) (also available from Prolmmune, USA).

All procedures including procedures involving animal or human cells were conducted in accordance with all relevant guidelines and procedures per approved IRB and Animal welfare committee (AWC) protocols of UT Health Sciences Center.

\section{Reporting summary}

Further information on experimental design is available in the Nature Research Reporting Summary linked to this article.

\section{DATA AVAILABILITY}

The data supporting the figures are available from the authors after approval of institutional IP-related regulations.

\section{ACKNOWLEDGEMENTS}

This study was supported by NIH NIAID AI49534 (C.J.); AI78420 (C.J.); NHLBI HL080205 (N.T.E.); and P30 Al36211 (D.E.L.). Robert J. Kleberg and Helen C. Kleberg Foudnation (S.D.) are grateful to Dr. Cliff Harding and Dr. Henry Boom of CWRU, USA for providing BB7 T cells.

\section{AUTHOR CONTRIBUTIONS}

C.J. discovered TLR-activating peptide epitopes and along with RLH-designed experiments, A.K., P.B., S.S., E.S., and C.R.S. performed different experiments. S.D. designed the recombinant BCG constructs and S.S. and K.D. generated the BCG constructs. Y.M. and J.S. prepared the ESAT-6 truncated constructs. D.Z. and C.P. helped during assays with TLR-deficient mice. NTE assisted in the autophagy-related experiments. C.J. interpreted the data and wrote and edited the paper. S.D. and R.L.H. coedited the paper.

\section{ADDITIONAL INFORMATION}

Supplementary information accompanies the paper on the npj Vaccines website (https://doi.org/10.1038/s41541-019-0122-8).

Competing interests: The authors declare no competing interests.

Publisher's note: Springer Nature remains neutral with regard to jurisdictional claims in published maps and institutional affiliations.

\section{REFERENCES}

1. Colditz, G. A. et al. Efficacy of BCG vaccine in the prevention of tuberculosis. Meta-analysis of the published literature. JAMA 271, 698-702 (1994).

2. Rook, G. A., Hernandez-Pando, R., Dheda, K. \& Teng Seah, G. IL-4 in tuberculosis: implications for vaccine design. Trends Immunol. 25, 483-488 (2004).

3. Armitige, L. Y., Jagannath, C., Wanger, A. R. \& Norris, S. J. Disruption of the genes encoding antigen $85 \mathrm{~A}$ and antigen $85 \mathrm{~B}$ of Mycobacterium tuberculosis H37Rv: effect on growth in culture and in macrophages. Infect. Immun. 68, 767-778 (2000).

4. Katti, M. K. et al. The Delta fbpA mutant derived from Mycobacterium tuberculosis H37Rv has an enhanced susceptibility to intracellular antimicrobial oxidative mechanisms, undergoes limited phagosome maturation and activates macrophages and dendritic cells. Cell Microbiol. 10, 1286-1303 (2008).

5. Saikolappan, S. et al. The fbpA/sapM double knock out strain of Mycobacterium tuberculosis is highly attenuated and immunogenic in macrophages. PLOS ONE 7, e36198 (2011)

6. da Costa, A. C., Nogueira, S. V., Kipnis, A. \& Junqueira-Kipnis, A. P. Recombinant BCG: innovations on an old vaccine. Scope of BCG strains and strategies to improve long-lasting memory. Front Immunol. 5, 152 (2014).

7. Baldwin, S. L. et al. Protection against tuberculosis with homologous or heterologous protein/vector vaccine approaches is not dependent on CD8+T cells. J. Immunol. 191, 2514-2525 (2013). 
8. Pancholi, P., Mirza, A., Bhardwaj, N. \& Steinman, R. M. Sequestration from immune $\mathrm{CD} 4+\mathrm{T}$ cells of mycobacteria growing in human macrophages. Science 260, 984-986 (1993)

9. Armstrong, J. A. \& Hart, P. D. Phagosome-lysosome interactions in cultured macrophages infected with virulent tubercle bacilli. Reversal of the usual nonfusion pattern and observations on bacterial survivali. J. Exp. Med 142, 1-16 (1975).

10. Clemens, D. L. \& Horwitz, M. A. The Mycobacterium tuberculosis phagosome interacts with early endosomes and is accessible to exogenously administered transferrin. J. Exp. Med. 184, 1349-1355 (1996).

11. Russell, D. G. Mycobacterium tuberculosis: here today, and here tomorrow. Nat. Rev. Mol. Cell Biol. 2, 569-577 (2001).

12. Deretic, V., Via, L. E., Fratti, R. A. \& Deretic, D. Mycobacterial phagosome maturation, rab proteins, and intracellular trafficking. Electrophoresis 18, 2542-2547 (1997).

13. Singh, C. R. et al. Processing and presentation of a mycobacterial antigen $85 \mathrm{~B}$ epitope by murine macrophages is dependent on the phagosomal acquisition of vacuolar proton ATPase and in situ activation of cathepsin D. J. Immunol. 177, 3250-3259 (2006).

14. Jagannath, C. et al. Autophagy enhances the efficacy of BCG vaccine by increasing peptide presentation in mouse dendritic cells. Nat. Med. 15, 267-276 (2009).

15. Lee, H. K. et al. In vivo requirement for Atg5 in antigen presentation by dendritic cells. Immunity 32, 227-239 (2010).

16. Mannick, J. B. et al. mTOR inhibition improves immune function in the elderly. Sci. Transl. Med. 6, 268ra179 (2014).

17. Araki, K. et al. mTOR regulates memory CD8 T-cell differentiation. Nature 460, 108-112 (2009)

18. Copenhaver, R. H. et al. A mutant of Mycobacterium tuberculosis H37Rv that lacks expression of antigen $85 \mathrm{~A}$ is attenuated in mice but retains vaccinogenic potential. Infect. Immun. 72, 7084-7095 (2004).

19. Saikolappan, S. et al. The fbpA/sapM double knock out strain of Mycobacterium tuberculosis is highly attenuated and immunogenic in macrophages. PLOS ONE 7, e36198 (2012).

20. Jagannath, C., Khan, A. \& Wang, J. In Increased Immunogenicity Through Autophagy, (ed M.A. Hayat) 35-54 (Elsevier, NY, 2018).

21. Pym, A. S., Brodin, P., Brosch, R., Huerre, M. \& Cole, S. T. Loss of RD1 contributed to the attenuation of the live tuberculosis vaccines Mycobacterium bovis BCG and Mycobacterium microti. Mol. Microbiol. 46, 709-717 (2002).

22. Brandt, L., Elhay, M., Rosenkrands, I., Lindblad, E. B. \& Andersen, P. ESAT-6 subunit vaccination against Mycobacterium tuberculosis. Infect. Immun. $\mathbf{6 8}$ 791-795 (2000).

23. Pym, A. S. et al. Recombinant BCG exporting ESAT-6 confers enhanced protection against tuberculosis. Nat. Med. 9, 533-539 (2003).

24. Palendira, U., Spratt, J. M., Britton, W. J. \& Triccas, J. A. Expanding the antigenic repertoire of BCG improves protective efficacy against aerosol Mycobacterium tuberculosis infection. Vaccine 23, 1680-1685 (2005).

25. Pathak, S. K. et al. Direct extracellular interaction between the early secreted antigen ESAT- 6 of Mycobacterium tuberculosis and TLR2 inhibits TLR signaling in macrophages. Nat. Immunol. 8, 610-618 (2007).

26. Wang, X. et al. ESAT- 6 inhibits production of IFN-gamma by Mycobacterium tuberculosis-responsive human T cells. J. Immunol. 182, 3668-3677 (2009).

27. Samten, B., Wang, X. \& Barnes, P. F. Mycobacterium tuberculosis ESX-1 systemsecreted protein ESAT- 6 but not CFP10 inhibits human T-cell immune responses. Tuberc. (Edinb.) 89(Suppl 1), S74-S76 (2009).

28. Lewis, K. N. et al. Deletion of RD1 from Mycobacterium tuberculosis mimics bacille Calmette-Guerin attenuation. J. Infect. Dis. 187, 117-123 (2003).

29. Renshaw, P. S. et al. Structure and function of the complex formed by the tuberculosis virulence factors CFP-10 and ESAT-6. Embo J. 24, 2491-2498 (2005).

30. Renshaw, P. S. et al. Conclusive evidence that the major T-cell antigens of the Mycobacterium tuberculosis complex ESAT-6 and CFP-10 form a tight, 1:1 complex and characterization of the structural properties of ESAT-6, CFP-10, and the ESAT-6*CFP-10 complex. Implications for pathogenesis and virulence. J. Biol. Chem. 277, 21598-21603 (2002).

31. Marei, A. et al. Superior T cell activation by ESAT- 6 as compared with the ESAT- 6 CFP-10 complex. Int Immunol. 17, 1439-1446 (2005).

32. de Jonge, M. I. et al. ESAT-6 from Mycobacterium tuberculosis dissociates from its putative chaperone CFP-10 under acidic conditions and exhibits membranelysing activity. J. Bacteriol. 189, 6028-6034 (2007).

33. Ganguly, N. et al. Mycobacterium tuberculosis secretory proteins CFP-10, ESAT-6 and the CFP10:ESAT6 complex inhibit lipopolysaccharide-induced NF-kappaB transactivation by downregulation of reactive oxidative species (ROS) production. Immunol. Cell Biol. 86, 98-106 (2008).

34. Dietrich, J., Weldingh, K. \& Andersen, P. Prospects for a novel vaccine against tuberculosis. Vet. Microbiol. 112, 163-169 (2006).
35. Ramachandra, L., Noss, E., Boom, W. H. \& Harding, C. V. Phagocytic processing of antigens for presentation by class II major histocompatibility complex molecules. Cell Microbiol. 1, 205-214 (1999).

36. Ramachandra, L., Noss, E., Boom, W. H. \& Harding, C. V. Processing of Mycobacterium tuberculosis antigen $85 \mathrm{~B}$ involves intraphagosomal formation of peptide-major histocompatibility complex II complexes and is inhibited by live bacilli that decrease phagosome maturation. J. Exp. Med. 194, 1421-1432 (2001).

37. Lightbody, K. L. et al. Characterisation of complex formation between members of the Mycobacterium tuberculosis complex CFP-10/ESAT-6 protein family: towards an understanding of the rules governing complex formation and thereby functional flexibility. FEMS Microbiol. Lett. 238, 255-262 (2004).

38. Lightbody, K. L. et al. Molecular features governing the stability and specificity of functional complex formation by Mycobacterium tuberculosis CFP-10/ESAT-6 family proteins. J. Biol. Chem. 283, 17681-17690 (2008).

39. Bao, L., Chen, W., Zhang, H. \& Wang, X. Virulence, immunogenicity, and protective efficacy of two recombinant Mycobacterium bovis bacillus CalmetteGuerin strains expressing the antigen ESAT-6 from Mycobacterium tuberculosis. Infect. Immun. 71, 1656-1661 (2003).

40. Kamath, A. B. et al. Cytolytic CD8+T cells recognizing CFP10 are recruited to the lung after Mycobacterium tuberculosis infection. J. Exp. Med. 200, 1479-1489 (2004).

41. Wu, Y., Woodworth, J. S., Shin, D. S., Morris, S. \& Behar, S. M. Vaccine-elicited 10kilodalton culture filtrate protein-specific CD8+T cells are sufficient to mediate protection against Mycobacterium tuberculosis infection. Infect. Immun. 76 , 2249-2255 (2008)

42. Pasare, C. \& Medzhitov, R. Toll-like receptors: linking innate and adaptive immunity. Adv. Exp. Med Biol. 560, 11-18 (2005).

43. Noss, E. H. et al. Toll-like receptor 2-dependent inhibition of macrophage class II MHC expression and antigen processing by $19-\mathrm{kDa}$ lipoprotein of Mycobacterium tuberculosis. J. Immunol. 167, 910-918 (2001).

44. Lochamy, J., Rogers, E. M. \& Boss, J. M. CREB and phospho-CREB interact with RFX5 and CIITA to regulate MHC class II genes. Mol. Immunol. 44, 837-847 (2007).

45. Martins, I. et al. Pathologic expression of MHC class II is driven by mitogenactivated protein kinases. Eur. J. Immunol. 37, 788-797 (2007).

46. Bakhru, P. et al. BCG vaccine mediated reduction in the MHC-Il expression of macrophages and dendritic cells is reversed by activation of Toll-like receptors 7 and 9. Cell Immunol. 287, 53-61 (2014).

47. Moffat, J. M., Mintern, J. D. \& Villadangos, J. A. Control of MHC II antigen presentation by ubiquitination. Curr. Opin. Immunol. 25, 109-114 (2013).

48. Gehring, A. J. et al. The Mycobacterium tuberculosis 19-kilodalton lipoprotein inhibits gamma interferon-regulated HLA-DR and Fc gamma R1 on human macrophages through Toll-like receptor 2. Infect. Immun. 71, 4487-4497 (2003).

49. Gehring, A. J., Dobos, K. M., Belisle, J. T., Harding, C. V. \& Boom, W. H. Mycobacterium tuberculosis LprG (Rv1411c): a novel TLR-2 ligand that inhibits human macrophage class II MHC antigen processing. J. Immunol. 173, 2660-2668 (2004).

50. Munz, C. Of LAP, CUPS, and DRibbles-unconventional use of autophagy proteins for MHC restricted antigen presentation. Front Immunol. 6, 200 (2015).

51. Romao, S. \& Munz, C. LC3-associated phagocytosis. Autophagy 10, 526-528 (2014).

52. Sengupta, S. et al. Mycobacterium tuberculosis EsxL inhibits MHC-II expression by promoting hypermethylation in class-II transactivator loci in macrophages. J. Biol. Chem. 292, 6855-6868 (2017).

53. Horwitz, M. A. Recombinant BCG expressing Mycobacterium tuberculosis major extracellular proteins. Microbes Infect. 7, 947-954 (2005).

54. Horwitz, M. A. \& Harth, G. A new vaccine against tuberculosis affords greater survival after challenge than the current vaccine in the guinea pig model of pulmonary tuberculosis. Infect. Immun. 71, 1672-1679 (2003).

55. Baldwin, S. L. et al. Evaluation of new vaccines in the mouse and guinea pig model of tuberculosis. Infect. Immun. 66, 2951-2959 (1998).

56. Billeskov, R., Elvang, T. T., Andersen, P. L. \& Dietrich, J. The HyVac4 subunit vaccine efficiently boosts BCG-primed anti-mycobacterial protective immunity. PLoS ONE 7, e39909 (2012).

57. Kamath, A., Woodworth, J. S. \& Behar, S. M. Antigen-specific CD8+T cells and the development of central memory during Mycobacterium tuberculosis infection. J. Immunol. 177, 6361-6369 (2006).

58. Ancelet, L. R., Aldwell, F. E., Rich, F. J. \& Kirman, J. R. Oral vaccination with lipidformulated BCG induces a long-lived, multifunctional CD4(+) T cell memory immune response. PLoS One 7, e45888 (2012).

59. Wolf, A. J. et al. Initiation of the adaptive immune response to Mycobacterium tuberculosis depends on antigen production in the local lymph node, not the lungs. J. Exp. Med. 205, 105-115 (2008).

60. Orme, I. M. Current progress in tuberculosis vaccine development. Vaccine $\mathbf{2 3}$ 2105-2108 (2005) 
61. Kipnis, A., Irwin, S., Izzo, A. A., Basaraba, R. J. \& Orme, I. M. Memory T lymphocytes generated by Mycobacterium bovis BCG vaccination reside within a CD4 CD44lo CD62 ligand(hi) population. Infect. Immun. 73, 7759-7764 (2005).

62. Henao-Tamayo, M. I. et al. Phenotypic definition of effector and memory Tlymphocyte subsets in mice chronically infected with Mycobacterium tuberculosis. Clin. Vaccin. Immunol. 17, 618-625 (2010).

63. Henao-Tamayo, M. et al. A mouse model of tuberculosis reinfection. Tuberc. (Edinb.) 92, 211-217 (2012).

64. Opata, M. M. \& Stephens, R. Early decision: effector and effector memory t cell differentiation in chronic infection. Curr. Immunol. Rev. 9, 190-206 (2013).

65. Obar, J. J. et al. Pathogen-induced inflammatory environment controls effector and memory CD8+T cell differentiation. J. Immunol. 187, 4967-4978 (2011)

66. Obar, J. J. \& Lefrancois, L. Early events governing memory CD8+T-cell differentiation. Int Immunol. 22, 619-625 (2010).

67. Obar, J. J. \& Lefrancois, L. Memory CD8+T cell differentiation. Ann. N. Y Acad. Sci. 1183, 251-266 (2010).

68. Caruso, A. M. et al. Mice deficient in CD4 T cells have only transiently diminished levels of IFN-gamma, yet succumb to tuberculosis. J. Immunol. 162, 5407-5416 (1999).

69. Stenger, S. \& Modlin, R. L. T cell mediated immunity to Mycobacterium tuberculosis. Curr. Opin. Microbiol 2, 89-93 (1999).

70. Hess, J. et al. Mycobacterium bovis Bacille Calmette-Guerin strains secreting listeriolysin of Listeria monocytogenes. Proc. Natl Acad. Sci. USA 95, 5299-5304 (1998).

71. Irwin, S. M. et al. Tracking antigen-specific CD8 T lymphocytes in the lungs of mice vaccinated with the Mtb72F polyprotein. Infect. Immun. 73, 5809-5816 (2005).

72. Kaveh, D. A., Bachy, V. S., Hewinson, R. G. \& Hogarth, P. J. Systemic BCG immunization induces persistent lung mucosal multifunctional CD4 T(EM) cells which expand following virulent mycobacterial challenge. PLOS ONE 6, e21566 (2011).

73. Canaday, D. H. et al. CD4(+) and CD8(+) T cells kill intracellular Mycobacterium tuberculosis by a perforin and Fas/Fas ligand-independent mechanism. J. Immunol. 167, 2734-2742 (2001).

74. Andersen, P. \& Woodworth, J. S. Tuberculosis vaccines-rethinking the current paradigm. Trends Immunol. 35,81-93 (2014).

75. Kaech, S. M., Wherry, E. J. \& Ahmed, R. Effector and memory T-cell differentiation: implications for vaccine development. Nat. Rev. Immunol. 2, 251-262 (2002).

76. Henao-Tamayo, M. et al. A mouse model of tuberculosis reinfection. Tuberc. (Edinb) 92, 211-217 (2012).

77. Banerjee, A. et al. Cutting edge: the transcription factor eomesodermin enables CD8+T cells to compete for the memory cell niche. J. Immunol. 185, 4988-4992 (2010).

78. Levy, O. \& Levy, O. Ready to benefit from training: heterologous effects of early life immunization. Trans. R. Soc. Trop. Med. Hyg. 109, 3-4 (2015).

79. Jensen, K. J. et al. Heterologous immunological effects of early BCG vaccination in low-birth-weight infants in Guinea-Bissau: a randomized-controlled trial. J. Infect. Dis. 211, 956-967 (2015).

80. van den Biggelaar, A. H. et al. Neonatal innate cytokine responses to BCG controlling T-cell development vary between populations. J. Allergy Clin. Immunol. 124, 544-550 (2009). 550 e1-2.

81. Marchant, A. et al. Newborns develop a Th1-type immune response to Mycobacterium bovis bacillus Calmette-Guerin vaccination. J. Immunol. 163, 2249-2255 (1999).

82. Dye, C. Making wider use of the world's most widely used vaccine: Bacille Calmette-Guerin revaccination reconsidered. J. R. Soc. Interface 10, 20130365 (2013).

83. Chelvarajan, R. L. et al. Defective macrophage function in neonates and its impact on unresponsiveness of neonates to polysaccharide antigens. J. Leukoc. Biol. 75, 982-994 (2004).

84. Karlsson, H., Hessle, C. \& Rudin, A. Innate immune responses of human neonatal cells to bacteria from the normal gastrointestinal flora. Infect. Immun. 70, 6688-6696 (2002).

85. Caron, J. E., La Pine, T. R., Augustine, N. H., Martins, T. B. \& Hill, H. R. Multiplex analysis of toll-like receptor-stimulated neonatal cytokine response. Neonatology 97, 266-273 (2010).

86. Vanden Eijnden, S., Goriely, S., De Wit, D., Goldman, M. \& Willems, F. Preferential production of the IL-12(p40)/IL-23(p19) heterodimer by dendritic cells from human newborns. Eur. J. Immunol. 36, 21-26 (2006).

87. Vanden Driessche, K., Persson, A., Marais, B. J., Fink, P. J. \& Urdahl, K. B. Immune vulnerability of infants to tuberculosis. Clin. Dev. Immunol. 2013, 781320 (2013)

88. Dalgic, N. et al. Arg753GIn polymorphism of the human Toll-like receptor 2 gene from infection to disease in pediatric tuberculosis. Hum. Immunol. 72, 440-445 (2011).
89. Lykouras, D. et al. Human genes in TB infection: their role in immune response. Monaldi Arch. Chest Dis. 69, 24-31 (2008).

90. Singh, C. R., Bakhru, P., Khan, A., Li, Q. B. \& Jagannath, C. Cutting edge: Nicastrin and related components of gamma-secretase generate a peptide epitope facilitating immune recognition of intracellular mycobacteria, through MHC class II-dependent priming of T cells. J. Immunol. 187, 5495-5499 (2011).

91. Jagannath, C. \& Bakhru, P. Rapamycin-induced enhancement of vaccine efficacy in mice. Methods Mol. Biol. 821, 295-303 (2012).

92. Uhl, M. et al. Autophagy within the antigen donor cell facilitates efficient antigen cross-priming of virus-specific CD8+T cells. Cell Death Differ. 16, 991-1005 (2009).

93. Chatterjee, S. et al. Early secreted antigen ESAT-6 of Mycobacterium tuberculosis promotes protective $\mathrm{T}$ helper 17 cell responses in a toll-like receptor-2dependent manner. PLoS Pathog. 7, e1002378 (2011).

94. Rahman, A., Sobia, P., Gupta, N., Kaer, L. V. \& Das, G. Mycobacterium tuberculosis subverts the TLR-2-MyD88 pathway to facilitate its translocation into the cytosol. PLOS ONE 9, e86886 (2014).

95. Essone, P. N. et al. Host cytokine responses induced after overnight stimulation with novel $M$. tuberculosis infection phase-dependent antigens show promise as diagnostic candidates for TB disease. PLOS ONE 9, e102584 (2014).

96. Vergne, I. et al. Mechanism of phagolysosome biogenesis block by viable Mycobacterium tuberculosis. Proc. Natl Acad. Sci. USA 102, 4033-4038 (2005).

97. Gengenbacher, M. et al. Deletion of nuoG from the vaccine candidate Mycobacterium bovis BCG DeltaureC:hly improves protection against tuberculosis. MBio 7, pii: e00679-16 (2016).

98. Romao, S. et al. Autophagy proteins stabilize pathogen-containing phagosomes for prolonged MHC II antigen processing. J. Cell Biol. 203, 757-766 (2013).

99. $\mathrm{Xu}, \mathrm{Y}$. et al. Toll-like receptor 4 is a sensor for autophagy associated with innate immunity. Immunity 27, 135-144 (2007).

100. Fulton, S. A. et al. Inhibition of major histocompatibility complex II expression and antigen processing in murine alveolar macrophages by Mycobacterium bovis BCG and the 19-kilodalton mycobacterial lipoprotein. Infect. Immun. 72, 2101-2110 (2004).

101. Tobian, A. A. et al. Alternate class I MHC antigen processing is inhibited by Tolllike receptor signaling pathogen-associated molecular patterns: Mycobacterium tuberculosis 19-kDa lipoprotein, CpG DNA, and lipopolysaccharide. J. Immunol. 171, 1413-1422 (2003).

102. Pai, R. K., Convery, M., Hamilton, T. A., Boom, W. H. \& Harding, C. V. Inhibition of IFN-gamma-induced class II transactivator expression by a $19-\mathrm{kDa}$ lipoprotein from Mycobacterium tuberculosis: a potential mechanism for immune evasion. J. Immunol. 171, 175-184 (2003).

103. Tsuji, S. et al. Maturation of human dendritic cells by cell wall skeleton of Mycobacterium bovis bacillus Calmette-Guerin: involvement of toll-like receptors. Infect. Immun. 68, 6883-6890 (2000).

104. Sander, B. et al. Sequential production of Th1 and Th2 cytokines in response to live bacillus Calmette-Guerin. Immunology 86, 512-518 (1995).

105. Zenha, E. M. et al. Clinical and immunological evaluation after BCG-id vaccine in leprosy patients in a 5-year follow-up study. J. Inflamm. Res. 5, 125-135 (2012).

106. Harris, J. Autophagy and IL-1 family cytokines. Front Immunol. 4, 83 (2013).

107. Shafiani, S. et al. Pathogen-specific Treg cells expand early during mycobacterium tuberculosis infection but are later eliminated in response to Interleukin-12. Immunity 38, 1261-1270 (2013).

108. Yeo, C. J. \& Fearon, D. T. T-bet-mediated differentiation of the activated CD8+T cell. Eur. J. Immunol. 41, 60-66 (2011).

109. Falvo, J. V., Jasenosky, L. D., Kruidenier, L. \& Goldfeld, A. E. Epigenetic control of cytokine gene expression: regulation of the TNF/LT locus and T helper cell differentiation. Adv. Immunol. 118, 37-128 (2013).

110. O'Sullivan, B. J. et al. IL-1 beta breaks tolerance through expansion of CD25 +effector T cells. J. Immunol. 176, 7278-7287 (2006).

111. Dietrich, J. et al. Exchanging ESAT6 with TB10.4 in an Ag85B fusion moleculebased tuberculosis subunit vaccine: efficient protection and ESAT6-based sensitive monitoring of vaccine efficacy. J. Immunol. 174, 6332-6339 (2005).

112. Spencer, A. J. et al. Fusion of the Mycobacterium tuberculosis antigen $85 \mathrm{~A}$ to an oligomerization domain enhances its immunogenicity in both mice and nonhuman primates. PLoS ONE 7, e33555 (2012).

113. Orme, I. M. The Achilles heel of BCG. Tuberculosis (Edinb) 90, 329-332 (2010).

114. Obar, J. J. \& Lefrancois, L. Early signals during CD8 T cell priming regulate the generation of central memory cells. J. Immunol. 185, 263-272 (2010).

115. McLane, L. M. et al. Differential localization of T-bet and Eomes in CD8 T cell memory populations. J. Immunol. 190, 3207-3215 (2013).

116. Intlekofer, A. M. et al. Effector and memory CD8+T cell fate coupled by T-bet and eomesodermin. Nat. Immunol. 6, 1236-1244 (2005).

117. Swain, S. L. \& Bradley, L. M. Helper T cell memory: more questions than answers. Semin Immunol. 4, 59-68 (1992). 
118. Blair, D. A. et al. Duration of antigen availability influences the expansion and memory differentiation of T cells. J. Immunol. 187, 2310-2321 (2011).

119. Kasturi, S. P. et al. Programming the magnitude and persistence of antibody responses with innate immunity. Nature 470, 543-547 (2011).

120. van Dissel, J. T. et al. Ag85B-ESAT-6 adjuvanted with IC31 promotes strong and long-lived Mycobacterium tuberculosis specific $T$ cell responses in naive human volunteers. Vaccine 28, 3571-3581 (2010).

121. Kleinnijenhuis, J. et al. Bacille Calmette-Guerin induces NOD2-dependent nonspecific protection from reinfection via epigenetic reprogramming of monocytes. Proc. Natl Acad. Sci. USA 109, 17537-17542 (2012).

122. De Leon, J. et al. Mycobacterium tuberculosis ESAT-6 exhibits a unique membrane-interacting activity that is not found in its ortholog from nonpathogenic Mycobacterium smegmatis. J. Biol. Chem. 287, 44184-44191 (2012).

123. Ma, Y., Keil, V. \& Sun, J. Characterization of Mycobacterium tuberculosis EsxA membrane insertion: roles of $\mathrm{N}$ - and $\mathrm{C}$-terminal flexible arms and central helixturn-helix motif. J. Biol. Chem. 290, 7314-7322 (2015).

124. Roche, C. M. et al. The DeltafbpA attenuated candidate vaccine from Mycobacteriumtuberculosis, H37Rv primes for a stronger T-bet dependent Th1 immunity in mice. Tuberc. (Edinb.) 91 (Suppl 1), S96-S104 (2011).

125. Griffin, J. P. \& Orme, I. M. Evolution of CD4 T-cell subsets following infection of naive and memory immune mice with Mycobacterium tuberculosis. Infect. Immun. 62, 1683-1690 (1994).

126. Begum, D. et al. Accelerated induction of mycobacterial antigen-specific CD8 $+\mathrm{T}$ cells in the Mycobacterium tuberculosis-infected lung by subcutaneous vaccination with Mycobacterium bovis bacille Calmette-Guerin. Immunology 128, 556-563 (2009).

127. Billeskov, R., Vingsbo-Lundberg, C., Andersen, P. \& Dietrich, J. Induction of CD8 T cells against a novel epitope in TB10.4: correlation with mycobacterial virulence and the presence of a functional region of difference-1. J. Immunol. 179, 3973-3981 (2007)

128. Romano, M. et al. Induction of in vivo functional Db-restricted cytolytic T cell activity against a putative phosphate transport receptor of Mycobacterium tuberculosis. J. Immunol. 172, 6913-6921 (2004).

Attribution 4.0 International License, which permits use, sharing, adaptation, distribution and reproduction in any medium or format, as long as you give appropriate credit to the original author(s) and the source, provide a link to the Creative Commons license, and indicate if changes were made. The images or other third party material in this article are included in the article's Creative Commons license, unless indicated otherwise in a credit line to the material. If material is not included in the article's Creative Commons license and your intended use is not permitted by statutory regulation or exceeds the permitted use, you will need to obtain permission directly from the copyright holder. To view a copy of this license, visit http://creativecommons. org/licenses/by/4.0/.

(c) The Author(s) 2019 